Document downloaded from:

http://hdl.handle.net/10251/46102

This paper must be cited as:

Li ., L.; Zhou ., H.; Gómez-Hernández, JJ.; HENDRIKUS JOHANNES HENDRICKS-

FRANSSEN (2012). Jointly mapping hydraulic conductivity and porosity by assimilating concentration data via ensemble Kalman filter. Journal of Hydrology. 428:152-169. doi:10.1016/j.jhydrol.2012.01.037.

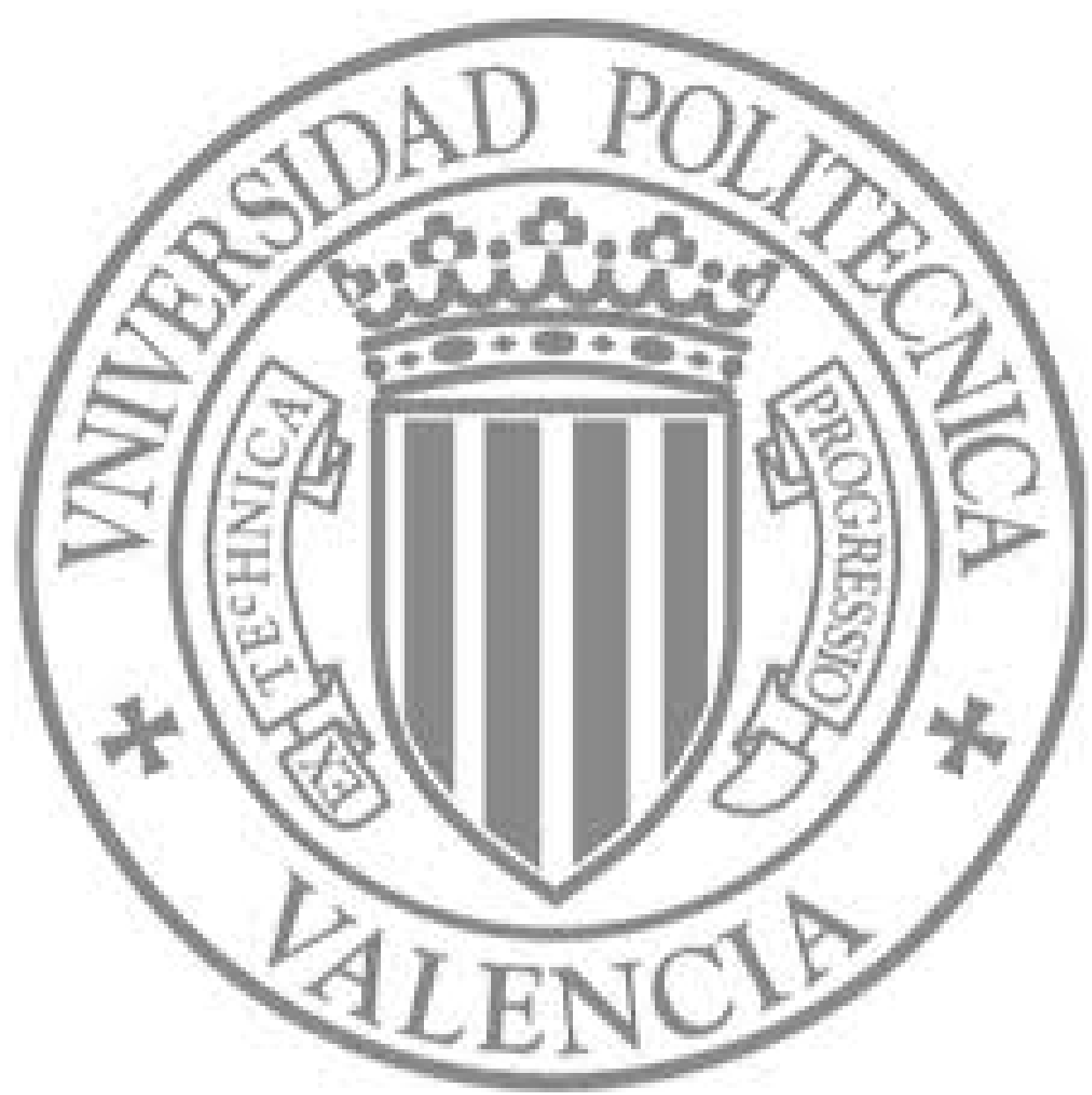

The final publication is available at

http://dx.doi.org/10.1016/j.jhydrol.2012.01.037

Copyright Elsevier 


\title{
Jointly Mapping Hydraulic Conductivity and Porosity by Assimilating Concentration Data via Ensemble Kalman Filter
}

\author{
Liangping Li ${ }^{*, a}$, Haiyan Zhou ${ }^{a}$, J. Jaime Gómez-Hernández ${ }^{\mathrm{a}}$, Harrie-Jan Hendricks Franssen ${ }^{\mathrm{b}}$ \\ ${ }^{a}$ Group of Hydrogeology, Universitat Politècnica de València, Camino de Vera, s/n, 46022 Valencia, Spain \\ ${ }^{b}$ Agrosphere, IBG-3, Forschungszentrum Jülich GmbH, 52425 Jülich, Germany
}

\begin{abstract}
Real-time data from on-line sensors offer the possibility to update environmental simulation models in realtime. Information from on-line sensors concerning contaminant concentrations in groundwater allow for the real-time characterization and control of a contaminant plume. In this paper it is proposed to use the CPU-efficient Ensemble Kalman Filter (EnKF) method, a data assimilation algorithm, for jointly updating the flow and transport parameters (hydraulic conductivity and porosity) and state variables (piezometric head and concentration) of a groundwater flow and contaminant transport problem. A synthetic experiment is used to demonstrate the capability of the EnKF to estimate hydraulic conductivity and porosity by assimilating dynamic head and multiple concentration data in a transient flow and transport model. In this work the worth of hydraulic conductivity, porosity, piezometric head, and concentration data is analyzed in the context of aquifer characterization and prediction uncertainty reduction. The results indicate that the characterization of the hydraulic conductivity and porosity fields is continuously improved as more data are assimilated. Also, groundwater flow and mass transport predictions are improved as more and different types of data are assimilated. The beneficial impact of accounting for multiple concentration data is patent. Key words: Data assimilation; stochastic transport; ensemble Kalman filter; multiple concentration data; hydraulic conductivity and porosity; heterogeneity
\end{abstract}

\section{Introduction}

During the last several decades numerical simulation is routinely utilized to evaluate the groundwater resources and predict the fate of contaminant plumes. The adequate characterization of spatially distributed hydrogeological parameters like hydraulic conductivity and porosity plays an important role in groundwater

\footnotetext{
*Corresponding author. Tel: +34 963879615 Fax: +34 963879492

Email addresses: liali@upvnet.upv.es (Liangping Li), haizh@upvnet.upv.es (Haiyan Zhou), jaime@dihma.upv.es (J. Jaime Gómez-Hernández), h.hendricks-franssen@fz-juelich.de (Harrie-Jan Hendricks Franssen)
} 
flow and transport simulations. However, due to the scarcity of measurements in combination with the large spatial heterogeneity it is not trivial how to characterize the spatial distribution of the mentioned parameters, and, consequently, groundwater flow and transport predictions call for an uncertainty assessment. Inverse modeling is often used to reduce model uncertainty by jointly conditioning on hard data (e.g., hydraulic conductivity and porosity) and indirect data (e.g., the observed state information, such as piezometric heads, concentrations and temperatures) to characterize the spatial variation of hydrogeological parameters. The issue of how to condition on the direct measurements has been extensively investigated in the geostatistical literature (e.g., Journel, 1974; Gómez-Hernández and Srivastava, 1990; Strebelle, 2002). Likewise, inverse modeling, i.e., conditioning to indirect data, has been reviewed in the literature (e.g., Yeh, 1986; McLaughlin and Townley, 1996; Zimmerman et al., 1998; Carrera et al., 2005; Hendricks Franssen et al., 2009). Commonly, inverse methods define an objective function that includes the mismatch between calculated and observed state values, as well as the perturbation of the initial parameter estimates. This objective function is minimized by an optimization approach. Examples are the self-calibration method (Sahuquillo et al., 1992; Gómez-Hernández et al., 1997; Capilla et al., 1999; Wen et al., 2002; Hendricks Franssen et al., 2003), the pilot point method (Ramarao et al., 1995; LaVenue et al., 1995; Alcolea et al., 2006), the Markov chain Monte Carlo method (Oliver et al., 1997), and the gradual deformation method (Hu, 2000; Capilla and Llopis-Albert, 2009).

Albeit the abundant literature on inverse conditioning of conductivities to piezometric head, only a few 23 works have paid attention on jointly conditioning on head and concentration data to improve the characteri24 zation of multiple hydrogeological parameters. Medina and Carrera (1996) extended the maximum likelihood approach (Carrera and Neuman, 1986) to condition on concentration data for a better characterization of zoned hydraulic conductivity maps. The main shortcoming of this approach is that the small-scale heterogeneity is ignored due to the estimation of hydraulic conductivity for larger zones. Hendricks Franssen et al. (1999) calibrated both hydraulic conductivity and storativity by conditioning to transient head data using the self-calibration method (Gómez-Hernández et al., 1997). More recently, Hendricks Franssen et al. (2003) further extended the self-calibration method to calibrate hydraulic conductivity by conditioning on piezometric head and concentration data. Huang et al. (2004) also employed the self-calibration method to jointly identify hydraulic conductivity and sorption partitioning coefficient by conditioning on tracer breakthrough data. Fu and Gómez-Hernández (2009) employed the block Markov chain Monte Carlo method to calibrate conductivity by jointly conditioning to head and travel time data. Llopis-Albert and Capilla (2009) utilized the gradual deformation method to estimate the conductivity by incorporating head, concentration and travel 
time data. Schwede and Cirpka (2009) used the quasi-linear geostatistical approach of Kitanidis (1995) to estimate conductivity by conditioning on steady-state concentration measurements. Barnhart et al. (2010) employed PEST (Doherty, 2004), a model-independent nonlinear parameter estimation program, to calibrate hydraulic conductivity by conditioning to concentration data collected from wireless sensor networks. These approaches are able to generate multiple equally-likely parameter fields conditional to static and dynamic measurements, thus capable of depicting small-scale variability of hydraulic conductivity. However, the main shortcoming of those methods is that they are CPU-intensive; these methods require running the forward model multiple times during the iterative optimization process of each realization.

The Ensemble Kalman Filter (EnKF) (Burgers et al., 1998; Evensen, 2003), based on the sequential Bayesian updating rule, can be used to obtain results similar to those obtained by Monte-Carlo (MC) type inverse methods but with reduced CPU time (see section 2.2), and it is also flexible to incorporate multiple sources of uncertainty. Hendricks Franssen and Kinzelbach (2009) carried out a synthetic exercise and demonstrated that EnKF needs around a factor of 80 less CPU time than the self-calibration method to attain similar results. The EnKF can also handle data from on-line sensors that become available in real-time and assimilate them into an on-line model. The traditional inverse methods are not well suited to assimilate information that becomes available in real-time. EnKF provides an ensemble of updated stochastic realizations which can be used for uncertainty analysis.

The EnKF is increasingly applied, in atmospheric sciences, land-atmosphere interaction, petroleum engineering and hydrogeology (e.g. Anderson, 2001; Reichle et al., 2002; Wen and Chen, 2005; Chen and Zhang, 2006; Nowak, 2009; Hendricks Franssen et al., 2011; Zhou et al., 2011b). In atmospheric sciences or land surface models in general only the model states are updated, whereas in petroleum engineering and hydrogeology both system parameters and state variables are commonly addressed (Naevdal et al., 2005).

The EnKF has been successfully applied to assimilate dynamic piezometric head data to improve model predictions (e.g., Chen and Zhang, 2006; Hendricks Franssen and Kinzelbach, 2008; Sun et al., 2009; Li et al., 2011c; Zhou et al., 2011a). With regard to assimilating concentration data, Huang et al. (2008) conducted a synthetic experiment and calibrated hydraulic conductivity fields by assimilating piezometric head and concentration data. In their experiment, flow was at steady-state. Liu et al. (2008) estimated multiple parameters (i.e., hydraulic conductivity, dispersivities, mobile/immobile porosities) by assimilating piezometric head and concentration data in the steady-state flow model for the MADE site. It is worth to note that they used constant values as the prior estimates for the mentioned parameters, and perturbed the parameters, by assimilating observation data via EnKF, to yield heterogeneous fields. Our aim is to 
quantify the uncertainty of parameters and states starting with heterogeneous fields by conditioning on the direct measurements. Schöniger et al. (2011) assimilated normal-score transformed concentration data to calibrate hydraulic conductivities. They concluded that the improvement by the normal-score transformation (as compared with the classical EnKF, which uses untransformed data) is limited because after univariate normal transformation of the state variable, the concentration distribution is far from multi-Gaussian.

In comparison with the effort devoted to characterize the spatial variability of hydraulic conductivity by conditioning state information, less attention has been paid to identifying the spatial variability of porosity, probably due to its relatively small spatial variability ranging from 0.1 to 0.55 in unconsolidated granular aquifers (Freeze and Cherry, 1979). Additionally, various authors (e.g., Hassan, 2001; Riva et al., 2008; Hu et al., 2009; Jiang et al., 2010) have demonstrated (both in synthetic examples and real aquifers) the significance of accounting for the heterogeneity of porosity on predictions of solute movement.

We will demonstrate the capability of the EnKF to jointly map the hydraulic conductivity and porosity fields by assimilating dynamic piezometric head and multiple concentration data. Few studies have considered the conditioning with help of both multiple concentration data and dynamic piezometric head data to characterize unknown parameters. Also, to the best of our knowledge, this is the first work proposing the joint estimation of spatially distributed hydraulic conductivity and porosity fields in hydrogeology.

The remaining of this paper is organized as follows. We first summarize in section 2 the mathematical framework of the EnKF and discuss the jointly mapping of hydraulic conductivity and porosity by assimilating multiple concentration data. In section 3 , a synthetic example is used to demonstrate the effectiveness of the EnKF. The paper ends with summary and conclusions in section 4.

\section{Data Assimilation with the EnKF}

First, the flow and transport equations (i.e, the transfer functions) will be presented, and then the algorithm of EnKF is introduced with emphasis on the assimilation of concentration data.

\subsection{Flow and Transport Equations}

The well known flow equation of an incompressible or slightly compressible fluid in saturated porous media can be expressed by combining Darcy's Law and the continuity equation (Bear, 1972; Freeze and Cherry, 1979):

$$
\nabla \cdot(K \nabla h)=S \frac{\partial h}{\partial t}+W
$$


where $K$ is the hydraulic conductivity $\left[L T^{-1}\right]$ (which, without loss of generality, will be considered as a scalar at the characterization scale), $h$ is the piezometric head $[L] ; W$ represents sources or $\operatorname{sinks}\left[L^{3} T^{-1}\right]$; $S$ is the specific storage coefficient $\left[L^{-1}\right] ; t$ is the time $[T] ; \nabla \cdot=(\partial / \partial x+\partial / \partial y+\partial / \partial z)$ is the divergence operator of a vector field, and $\nabla=(\partial / \partial x, \partial / \partial y, \partial / \partial z)^{T}$ is the gradient operator of a scalar field.

Solute transport with linear equilibrium adsorption is governed by the following differential equation (Bear, 1972; Freeze and Cherry, 1979):

$$
\phi R \frac{\partial c}{\partial t}=\nabla(\phi \mathbf{D} \cdot \nabla c)-\nabla \mathbf{q} c
$$

where $c$ is solute concentration of solute in the water phase $\left[M L^{-3}\right] ; \phi$ is the porosity [dimensionless]; D is the local hydrodynamic dispersion coefficient tensor $\left[L^{2} T^{-1}\right]$, with eigenvalues associated with principal axes parallel and perpendicular to the direction of flow, defined as $D_{I}=\alpha_{L}|\mathbf{q}|+D_{m}, D_{I I}=\alpha_{T}|\mathbf{q}|+D_{m}$, $D_{I I I}=\alpha_{T}|\mathbf{q}|+D_{m}\left(\alpha_{L}\right.$ and $\alpha_{T}$ are respectively the longitudinal and transverse pore-scale dispersivity; $D_{m}$ is the molecular diffusion coefficient set to zero in this study, and $\mathbf{q}$ is the Darcy velocity given by $\mathbf{q}=-K \nabla h$ $\left.\left[L T^{-1}\right]\right)$; $\mathrm{R}$ is retardation factor expressed by $R=1+\rho_{b} K_{d} / \phi$ ( $\rho_{b}$ is the bulk density of soil; $K_{d}$ is the distribution coefficient).

\subsection{Ensemble Kalman Filter}

Extensive descriptions of EnKF and its algorithm can be found in Burgers et al. (1998) and Evensen (2003). Here, we mainly focus on the use of EnKF with updating both parameters (i.e., hydraulic conductivity and porosity) and states (i.e., piezometric head and concentration). It involves a forecast step and an analysis step, after the generation of the initial ensemble of hydraulic conductivity and porosity realizations.

- Step 1: Forecast model. The flow equation (1) or transport equation (2) is solved, i.e.,

$$
\mathbf{Y}_{k}=f\left(\mathbf{X}_{k-1}, \mathbf{Y}_{k-1}\right)
$$

where $\mathbf{Y}_{k}$ is the state of the system (piezometric heads and/or concentration data) at time step $t_{k}, f$ represents the groundwater flow and transport model (including boundary conditions, external stresses, and known parameters), and $\mathbf{X}_{k-1}$ denotes the model parameters (hydraulic conductivity 


$$
\left\{\begin{array}{lll}
\text { Case A }: \mathbf{X}=[\ln K]^{T} & \mathbf{Y}=[h]^{T}, & \text { if only } h \text { data are available. } \\
\text { Case B }: \mathbf{X}=[\ln K, \phi]^{T} & \mathbf{Y}=[c]^{T}, & \text { if only } c \text { data are available. } \\
\text { Case C }: \mathbf{X}=[\ln K, \boldsymbol{\phi}]^{T} & \mathbf{Y}=[h, c]^{T}, & \text { if } h \text { and } c \text { data are available. }
\end{array}\right.
$$

- Step 2: Analysis step. Using the observed dynamic piezometric head and concentration data, the model parameters are updated as follows:

1. Build the joint vector $\mathbf{\Psi}_{k}$, which includes the parameters $(\mathbf{X})$ and the forecasted state values $(\mathbf{Y})$. This vector can be split into as many members as there are realizations in the ensemble, with

$$
\mathbf{\Psi}_{k, j}=\left[\begin{array}{l}
\mathbf{X} \\
\mathbf{Y}
\end{array}\right]_{k, j}
$$

being the $j^{\text {th }}$ ensemble member of the augmented state vector at time $t_{k}$.

As an example, if the number of discretization blocks in the domain is $N_{k}$ and we are in case C, i.e., updating both $\ln K$ and $\phi$ using both $h$ and $c$ data, the dimension of vector $\boldsymbol{\Psi}_{k}$ will be $4 \times N_{k}$.

2. The joint vector is updated, realization by realization, by assimilating the observations $\left(\mathbf{Y}_{k}^{\text {obs }}\right)$ :

$$
\mathbf{\Psi}_{k, j}^{a}=\mathbf{\Psi}_{k, j}^{f}+\mathbf{G}_{k}\left(\mathbf{Y}_{k, j}^{o b s}+\boldsymbol{\epsilon}-\mathbf{H} \Psi_{k, j}^{f}\right),
$$

where the superscripts $a$ and $f$ denote analysis and forecast, respectively; $\epsilon$ is a random observation error vector; $\mathbf{H}$ is a linear operator that interpolates the forecasted heads to the measurement locations, and, in our case, is composed of $0^{\prime} s$ and $1^{\prime} s$ since we assume that measurements are taken at block centers. Therefore, equation (6) can be expressed as:

$$
\mathbf{\Psi}_{k, j}^{a}=\mathbf{\Psi}_{k, j}^{f}+\mathbf{G}_{k}\left(\mathbf{Y}_{k, j}^{o b s}+\boldsymbol{\epsilon}-\mathbf{Y}_{k, j}^{f}\right)
$$

where the Kalman gain $\mathbf{G}_{k}$ is given by:

$$
\mathbf{G}_{k}=\mathbf{P}_{k}^{f} \mathbf{H}^{T}\left(\mathbf{H P}_{k}^{f} \mathbf{H}^{T}+\mathbf{R}_{k}\right)^{-1}
$$

where $\mathbf{R}_{k}$ is the measurement error covariance matrix, and $\mathbf{P}_{k}^{f}$ contains the covariances between 
the different components of the state vector. $\mathbf{P}_{k}^{f}$ can be estimated from the ensemble of forecasted results as:

$$
\begin{aligned}
\mathbf{P}_{k}^{f} & \approx E\left[\left(\mathbf{\Psi}_{k, j}^{f}-\overline{\mathbf{\Psi}}_{k, j}^{f}\right)\left(\boldsymbol{\Psi}_{k, j}^{f}-\overline{\mathbf{\Psi}}_{k, j}^{f}\right)^{T}\right] \\
& \approx \sum_{j=1}^{N_{e}} \frac{\left(\boldsymbol{\Psi}_{k, j}^{f}-\overline{\mathbf{\Psi}}_{k, j}^{f}\right)\left(\mathbf{\Psi}_{k, j}^{f}-\overline{\mathbf{\Psi}}_{k, j}^{f}\right)^{T}}{N_{e}},
\end{aligned}
$$

where $N_{e}$ is the number of realizations in the ensemble, and the overbar denotes average over the ensemble.

In the implementation of the algorithm, it is not necessary to calculate explicitly the full covariance matrix $\mathbf{P}_{k}^{f}$ (of dimensions $\left(4 \times N_{k}\right) \times\left(4 \times N_{k}\right)$ for case C). The matrix $\mathbf{H}$ is very sparse, and, consquently, the matrices $\mathbf{P}_{k}^{f} \mathbf{H}^{T}$ and $\mathbf{H P}_{k}^{f} \mathbf{H}^{T}$ can be computed directly at a strongly reduced CPU cost.

- Step 3: Loop back. The updated states become the current states and the forecast-analysis loop is started again.

When the number of observation locations used in the assimilation step is not very large, the computational cost of calculating the covariances is limited. The main cost is related with the forward simulations for each of the stochastic realizations.

During the updating step, the forecasted state variables may have no physical meaning, e.g., negative concentrations. In our case, we remove negative values resetting them to zero. We have checked that when this may happen at locations far from the concentration plume and always with small values. This approach follows the one by Gu and Oliver (2006), who had a similar problem when dealing with water saturation in a reservoir characterization exercise.

The algorithm is implemented in the C software EnKF3D which is used in conjunction with finitedifference program MODFLOW (Harbaugh et al., 2000), to solve the confined transient flow equation (1), and the solute transport code MT3DMS (Zheng et al., 1999). MT3DMS uses a third-order total-variationdiminishing (TVD) solution scheme, to solve the transport equation (2).

\section{Synthetic Example}

In this section, a synthetic example will be presented to demonstrate the capability of the EnKF to calibrate the hydraulic conductivities and porosities by assimilating piezometric head and concentration 
data. The resulting ensemble of realizations will be used also for uncertainty characterization; in a realworld case study, uncertainty may stem both from the conceptual model (e.g., the boundary conditions, aquifer geometry) and from the parameters. Here, we only consider the uncertainty due to the heterogeneity of hydraulic conductivity and porosity, no conceptual uncertainty is considered.

\subsection{Experiment Setup}

\subsubsection{Reference Field}

The reference conductivity and porosity fields are generated using the code GCOSIM3D (Gómez-Hernández and Journel, 1993) over a domain of $250 \mathrm{~m} \times 250 \mathrm{~m} \times 1 \mathrm{~m}$, which is discretized into grid cells of size $5 \mathrm{~m}$ by $5 \mathrm{~m}$ by $1 \mathrm{~m}$ (see Figure 1A and 1C). Here, we assume that the two variables are independent of each other. The parameters of each random function are listed in Table 1. From these reference realizations nine conductivity and nine porosity data are sampled for conditioning purposes. The locations are shown in Figure 1B and 1D.

It is assumed that the sampled data have the same support as the grid cell. If the data support would be much smaller than the grid cell size, the additional problem of upscaling must be considered for generating the parameter realizations conditional to the direct measured data (e.g., Li et al., 2011a; Zhou et al., 2010; Li et al., 2011b).

The aquifer is assumed to be confined with impermeable boundaries on south and north, prescribed head values on the western boundary and constant flow rate on the eastern boundary (see Figure 2). The prescribed head value is $0 \mathrm{~m}$ along the western boundary. The total flow rate through the eastern boundary is $-25 \mathrm{~m}^{3} / \mathrm{d}$, distributed uniformly along the boundary. The initial head value is $0 \mathrm{~m}$ over the entire domain. The total simulation time is 500 days, and this period is discretized into 100 time steps following a geometric sequence of ration 1.05. Specific storage is assumed constant with a value of $0.003 \mathrm{~m}^{-1}$. The simulated dynamic piezometric heads at the observation wells \#1 to \#9 in Figure 2 are sampled and will be used as assimilating data. The simulated heads at the wells \#10 and \#11 will be used as validation data.

The boundary conditions for the transport model are no-mass flux boundaries on the western, northern, and southern borders of the model. The eastern border is a specified advective mass flux boundary, acting as a line of sinks taking mass out of the aquifer (see Figure 2).

The code MODFLOW (Harbaugh et al., 2000) is used to solve the transient groundwater flow equation for the reference field and the pore velocities across the grid cell interfaces are calculated using the porosities in Figure 1C. This velocity field is used as input for solving the solute transport problem with help of the 
MT3DMS code (Zheng et al., 1999). We only consider advection and dispersion as transport mechanisms with $\alpha_{L}=1.0 \mathrm{~m}$ and $\alpha_{T}=0.1 \mathrm{~m}$. Conservative solute is uniformly placed over a line transverse to the groundwater flow at time $t=0$ (see Figure 2). The source concentration is $900 \mathrm{ppm}$. To avoid the boundary effect as described by Naff et al. (1998), the contaminant source is separated $20 \mathrm{~m}$ from the western boundary and $50 \mathrm{~m}$ from the northern and southern boundaries. The plume snapshots at 300, 400 and 500 days will be used here to compare the EnKF solutions with the reference plume maps (see Figures $3 \mathrm{~A}, 3 \mathrm{C}$ and $3 \mathrm{E}$ ). The concentration is measured at 63 wells, uniformly distributed over the domain (see Figure 2). These measured multiple concentration data (see Figures 3B, 3D, 3F) will serve as assimilating data.

\subsubsection{Scenario Studies}

Six simulation scenarios are considered for which different types of measurement data are assimilated (see Table 2). Scenario 1 (S1) is an unconditional case. In Scenario 2 (S2) geostatistical simulation (GómezHernández and Journel, 1993) is used in order to condition on the nine measured hydraulic conductivities and the nine porosities shown in Figures 1B and 1D, repsectively. For S1 and S2, 500 realizations of hydraulic conductivity and porosity are generated using the same random functions as for the reference fields. Flow and transport are calculated for each of the $500 \ln K-\phi$ realization couples, without conditioning to head or concentration data.

For scenario 3 (S3) dynamic piezometric head data are used to update the geostatistical realizations conditioned on hydraulic conductivity and porosity data of scenario S2. Piezometric head data from wells \#1 to \#9 are sequentially assimilated for the first 60 time steps (approximately 67.7 days).

In scenarios 4, 5 and 6 (S4, S5, S6) concentration data are assimilated by EnKF, in addition to hydraulic conductivity data and piezometric head data. S4 uses concentration data at 400 days, S5 uses concentration data at 300 and 400 days, and S6 uses concentration data at 300, 400 and 500 days.

The piezometric head and concentration data are sampled from the reference simulations without error. However, during the assimilation process it is considered that the data might contain measurement errors and therefore a diagonal error covariance matrix was used, with all non-zero terms equal to $0.0025 \mathrm{~m}^{2}$ for head data and $0.0025 \mathrm{ppm}^{2}$ for concentration data. We note, in practice, the errors for the heads and concentration data would be not the same, and the observation errors would change with the time. From an operational point of view, it is straightforward to integrate them into the assimilation procedure.

\subsection{Assessment Measures}

The results for the six scenarios will be analyzed with the help of two metrics: 


$$
A A B(X)=\frac{1}{N_{b}} \sum_{i=1}^{N_{b}} \frac{1}{N_{e}} \sum_{r=1}^{N_{e}}\left|X_{i, r}-X_{r e f, i}\right|
$$

where $X_{i}$ is, either the $\log$ conductivity $\ln K$, porosity $\phi$, hydraulic head $h$ or concentration $c$, at location $i, X_{i, r}$ represents its value for realization $r, X_{r e f, i}$ is the reference value at location $i, N_{b}$ is number of nodes, and $N_{e}$ is the number of realizations in the ensemble (500, in this case).

2. The ensemble spread $(A E S P)$ represents the estimated uncertainty defined as follows:

$$
\operatorname{AESP}(X)=\left(\frac{1}{N_{b}} \sum_{i=1}^{N_{b}} \sigma_{X_{i}}^{2}\right)^{1 / 2},
$$

where $\sigma_{X_{i}}^{2}$ is the ensemble variance at location $i$.

The smaller the values for $A A B$ and $A E S P$, the better the prediction of variable $X$.

\subsection{Data Assimilation Results}

\subsubsection{Hydraulic Conductivities and Porosities}

Figures 4 and 5 show the ensemble mean and variance of the 500 logconductivity realizations for all six scenarios. Figures 6 and 7 show the ensemble mean and variance of the 500 porosity realizations and scenarios. The ensemble mean is used to check whether the main patterns of variability of the parameter are captured. In contrast to the individual realization showing distinctive patterns of high and low values, the ensemble means are smoothed representations of the spatial variability of the parameters. The ensemble variance illustrates how conditioning reduces the differences between the realizations.

In scenario 1 , with no conditional data, the ensemble mean and variance of $\ln K$ and $\phi$ are very close to the prior mean and variance. In scenario 2, using 9 conditioning hydraulic conductivities and porosities, the overall spatial patterns are captured, resulting in typical kriging maps. The ensemble variance maps show the typical bull-eye look of kriging maps, with zero variance at the sample locations and increasing variance away from them. The dynamic piezometric head data included in S3 help to capture better the main patterns of hydraulic conductivity with a further reduction of the variance. S4, S5 and S6 also include concentration data for conditioning. The ensemble mean maps better delineate the main patterns of variability, and at the same time, unlike previous scenarios with strongly smoothed representations of $\ln K$, also show some degree of the small-scale variability. The characterization of the main patterns of $\ln K$ improves quite remarkable 
with the conditioning of concentration data. For the scenario that uses the largest amount of conditioning data (S6), the patterns in the left upper corner of the area are identified very well, whereas this is not the case if only hydraulic conductivity, porosity and piezometric heads are used for conditioning. The role of concentration data on the characterization of porosity is also observable. The main patterns of porosity are clearer than without conditioning, and closer to the reference distribution. As expected, the ensemble variance, both for $\ln K$ and $\phi$, reduces further in $\mathrm{S} 6$ as compared with the other scenarios.

From a more quantitative point of view, the calculated two metrics (see Table 3) lead to similar conclusions. When the measured hydraulic conductivity, porosity, piezometric head and multiple concentration data are all used for conditioning (S6), the average absolute bias and the ensemble spread have the smallest values. More precisely, when conditioning to $\ln K$, the $A A B(\ln K)$ decreases $14 \%$ (S2 vs. S1), if we further condition to piezometric head, $A A B(\ln K)$ further decreases a $10 \%$ (S3 vs. S2), and there is an additional reduction of a $7 \%$ when conditioning to concentrations (S6 vs. S3). Likewise $A E S P(\ln K)$ goes down $12 \%$ from S1 to S2, an additional 16\% from S2 to S3 and 14\% more from S3 to S6. Similar results can be observed when analyzing the evolution of $A A B(\phi)$ and $A E S P(\phi)$. The $A A B(\phi)$ shows an $18 \%$ reduction as a consequence of conditioning to measured $\phi$ (S2 vs. S1), and 7\% additional reduction related with conditioning to concentration data (S6 vs. S2) and $\operatorname{AESP}(\phi)$ shows a $15 \%$ reduction as a consequence of conditioning to measured $\phi$ (S2 vs. S1), and 9\% additional reduction related with conditioning to concentration data (S6 vs. S2).

From these results, we can conclude that: (1) The direct measured hard data play the most important role to reduce the absolute bias of parameters; (2) The indirect measured head and concentration data reduce both the absolute bias and ensemble spread; (3) The best characterization of the aquifer in terms of $\ln K$ and $\phi$ is achieved by combining all the data.

\subsubsection{Piezometric Heads Reproduction}

Figure 8 shows the piezometric head evolution at well \#2 and \#10 for scenarios S1, S2, S3 and S6. Recall that the piezometric head data continuously collected from well \#1 to \#9 are used for conditioning, while wells \#10 and \#11 are for validation. Figure 8 shows that for S1 uncertainty is largest and that the uncertainty is reduced for increasing amounts of conditioning data. For S2 the uncertainty is still considerable, but if piezometric head data are used for conditioning (S3) the conditional well \#2 has a good head reproduction and the control well \#10, also shows a large reduction of spread. The measured head data play a critical role to reduce the uncertainty of predicted heads. The concentration data do not result in a further improvement of the characterization of hydraulic head since the dynamic heads are already 
reproduced very well in S3.

Table 4 shows the metrics regarding the piezometric head characterization at time $t=67.7$ days (i.e., the 60 th time step). The introduction of measured hydraulic conductivities attains around $27 \%$ reductions both for the $A A B(h)$ and $A E S P(h)$. An additional $66 \%$ reduction of $A A B(h)$ and $73 \%$ reduction of $A E S P(h)$ is achieved by conditioning to head data. The reductions of $A A B(h)$ and $A E S P(h)$ almost can be ignored when concentration data are used for conditioning in S4, S5 and S6.

The main conclusions are: (1) of all the data, the measured piezometric head data are most informative for improving head predictions and reducing the prediction uncertainty; (2) the impact of concentration data for characterizing piezometric head is very small.

\subsubsection{Concentrations Reproduction}

Figure 9 to 12 show the ensemble mean and variance of 500 concentration realizations at time 300 and 500 days resulting from the transport simulation for all the six scenarios.

These ensemble mean maps of concentration for scenario 1 show that even though each realization will have a non-Gaussian plume similar to those in the reference, the random location of high and low concentrations makes that the ensemble mean maps of plume show a Gaussian shape. Introducing the hydraulic conductivity data (S2) rectifies the plume but still does not reproduce the reference. The ensemble mean of the plume is further rectified when the conductivity, porosity and head data are jointly used for conditioning (S3). The reproduction of piezometric heads is very good in S3, but the limited improvement of the plume characterization indicates the importance of further conditioning on concentration data. The results for scenarios S4 and S6 show that conditioning remarkably improves the characterization of the plume. Conditioning to concentration data at $t=300$ days (S4) also improves strongly the prediction for 500 days (although the concentration data sampled at $t=500$ days are not used for conditioning in scenario S4). For scenarios S5 and S6 the additional concentration data from $t=400$ and 500 days improve further the characterization of the plume so that they are very close to the reference plumes.

The ensemble variance maps of the concentration fields show that the ensemble variance decreases away from the barycenter of the plume and is close to zero outside of the plume. The ensemble variance of concentration decreases continuously if more data are used for conditioning.

Table 5 shows the $A A B$ and $A E S P$ values for the concentrations at three times. Conditioning to hydraulic conductivity and porosity data (S2) results in an average $A A B$ reduction of $15 \%$ (compared with $\mathrm{S} 1$ ) and AESP reduces around 5\%. Additional conditioning to piezometric head data (S3), results on average in an additional $5 \%$ reduction of $A A B$ and an $A E S P$ reduction of around $7 \%$. Further conditioning 
to concentration data (S4, S5 and S6), yields prominent reduction of $A A B$ and $A E S P$ (on average $19 \%$ and $20 \%$, respectively).

We can see from the results: (1) concentration data is the type of data to most reduce the absolute bias and uncertainty of predicted concentration; $(2)$ the direct measured data and indirect head data also have an important impact on the predicted concentrations; (3) when all the data are considered, the concentration fields are best characterized.

\subsection{Reactive Transport Prediction Analysis}

In this subsection, a reactive transport prediction experiment is conducted with modified flow boundary conditions using the conductivity and porosity obtained in the data assimilation exercise to further demonstrate the robustness of EnKF.

The flow and transport configurations are the same as before but the flow is at steady-state. The eastern constant flow rate boundary condition is replaced with the constant head boundary condition $(h=-15 \mathrm{~m})$ and the solute mass is subject to sorption. Besides advection and dispersion also sorption according to a reversible linear equilibrium isotherm is considered with $\rho_{b}=1.81 \mathrm{~g} / \mathrm{cm}^{3}$ and $K_{d}=0.52 \mathrm{~cm}^{3} / \mathrm{g}$ ( $\operatorname{similar}$ to the values reported in the Borden aquifer (Mackay et al., 1986; Burr et al., 1994)). The reactive tracer is also released near the western boundary (see Figure 2) with the same total initial concentration. The plume snapshot at time $t=500$ days (see Figure 13) is used to evaluate the worth of the different data.

MODFLOW and MT3DMS are employed to solve the flow equation (1) and reactive transport equation (2), respectively.

Figure 14 shows the ensemble mean and variance of predicted concentration fields at $t=500$ days for the fields estimated from the scenarios S2, S3 and S6. It clearly shows that the predicted plume is close to the reference when multiple types of information are used for conditioning. Besides, the ensemble variance is the smallest for S6.

\section{Conclusion}

We have presented and demonstrated the Ensemble Kalman Filter, a data assimilation algorithm, to jointly estimate hydraulic conductivity and porosity by assimilating dynamic piezometric head and multiple concentration data in a hydrogeological stochastic model. Some of the attractive features of EnKF are the capability of assimilating data in real-time, CPU efficiency, ease of implementation without need of an adjoint model and the flexibility with regard to accounting for multiple sources of uncertainty jointly. 
We have used a synthetic example (1) to demonstrate the potential EnKF has to condition in a CPU efficient way to concentration data and (2) to analyze the worth of data for the characterization of aquifer parameters and states (with a special focus on solute concentrations). We have found that the head data have a distinctive impact to reduce the uncertainty of predicted piezometric head, but only a limited influence for improving the characterization of concentration distributions. Additional conditioning to multiple concentration data was shown to improve strongly the predicted solute plume and also the characterization of hydraulic conductivity and porosity.

Acknowledgements The authors gratefully acknowledge the financial support by ENRESA (project 0079000029) and the European Commission (project PAMINA). The second author also acknowledges the financial support from China Scholarship Council (CSC). Extra travel Grants awarded to the first and second author by the Ministry of Education (Spain) are also acknowledged.

\section{References}

Alcolea, A., Carrera, J., Medina, A., 2006. Pilot points method incorporating prior information for solving the groundwater flow inverse problem. Advances in Water Resources 29 (11), 1678-1689.

Anderson, J., 2001. An ensemble adjustment Kalman filter for data assimilation. Monthly weather review 129, 2884-2903.

Barnhart, K., Urteaga, I., Han, Q., Jayasumana, A., Illangasekare, T., 2010. On Integrating Groundwater Transport Models with Wireless Sensor Networks. Ground Water 48 (5), 771-780.

Bear, J., 1972. Dynamics of fluids in porous media. American Elsevier Pub. Co., New York.

Burgers, G., van Leeuwen, P., Evensen, G., 1998. Analysis scheme in the ensemble Kalman filter. Monthly Weather Review 126, 1719-1724.

Burr, D., Sudicky, E., Naff, R., 1994. Nonreactive and reactive solute transport in three-dimensional heterogeneous porous media: Mean displacement, plume spreading, and uncertainty. Water Resources Research $30(3), 791-815$.

Capilla, J., Llopis-Albert, C., 2009. Gradual conditioning of non-Gaussian transmissivity fields to flow and mass transport data: 1. Theory. Journal of Hydrology 371 (1-4), 66-74. 
Capilla, J. E., Rodrigo, J., Gómez-Hernández, J. J., 1999. Simulation of non-gaussian transmissivity fields honoring piezometric data and integrating soft and secondary information. Math. Geology 31 (7), 907-927.

Carrera, J., Alcolea, A., Medina, A., Hidalgo, J., Slooten, L., 2005. Inverse problem in hydrogeology. Hydrogeology Journal 13 (1), 206-222.

Carrera, J., Neuman, S., 1986. Estimation of aquifer parameters under transient and steady state conditions: 1. Maximum likelihood method incorporating prior information. Water Resources Research 22 (2), 199 210.

Chen, Y., Zhang, D., 2006. Data assimilation for transient flow in geologic formations via ensemble Kalman filter. Advances in Water Resources 29 (8), 1107-1122.

Doherty, J., 2004. PEST model-independent parameter estimation, user manual. Watermark Numerical Computing, Brisbane, Australia, 3349.

Evensen, G., 2003. The ensemble Kalman filter: Theoretical formulation and practical implementation. Ocean dynamics $53(4), 343-367$.

Freeze, R. A., Cherry, J. A., 1979. Groundwater. Prentice-Hall.

Fu, J., Gómez-Hernández, J., 2009. Uncertainty assessment and data worth in groundwater flow and mass transport modeling using a blocking Markov chain Monte Carlo method. Journal of Hydrology 364 (3-4), $328-341$

Gómez-Hernández, J. J., Journel, A. G., 1993. Joint sequential simulation of multi-Gaussian fields. Geostatistics Troia $92(1), 85-94$.

Gómez-Hernández, J. J., Sahuquillo, A., Capilla, J. E., 1997. Stochastic simulation of transmissivity fields conditional to both transmissivity and piezometric data, 1, Theory. Journal of Hydrology 203 (1-4), 162174.

Gómez-Hernández, J. J., Srivastava, R. M., 1990. ISIM3D: an ANSI-C three dimensional multiple indicator conditional simulation program. Computers \& Geosciences 16 (4), 395-440.

Gu, Y., Oliver, D., 2006. The ensemble Kalman filter for continuous updating of reservoir simulation models. Journal of Energy Resources Technology 128, 79. 
Harbaugh, A. W., Banta, E. R., Hill, M. C., McDonald, M. G., 2000. MODFLOW-2000, the U.S. Geological Survey modular ground-water model. U.S. Geological Survey, Branch of Information Services, Reston, VA, Denver, CO.

Hassan, A., 2001. Water flow and solute mass flux in heterogeneous porous formations with spatially random porosity. Journal of Hydrology 242 (1-2), 1-25.

Hendricks Franssen, H., Alcolea, A., Riva, M., Bakr, M., van der Wiel, N., Stauffer, F., Guadagnini, A., 2009. A comparison of seven methods for the inverse modelling of groundwater flow. application to the characterisation of well catchments. Advances in Water Resources 32 (6), 851-872.

Hendricks Franssen, H., Gómez-Hernández, J., Capilla, J., Sahuquillo, A., 1999. Joint simulation of transmissivity and storativity fields conditional to steady-state and transient hydraulic head data. Advances in Water Resources 23 (1), 1-13.

Hendricks Franssen, H., Gómez-Hernández, J., Sahuquillo, A., 2003. Coupled inverse modelling of groundwater flow and mass transport and the worth of concentration data. Journal of Hydrology 281 (4), 281-295.

Hendricks Franssen, H., H. P. Kaiser, U. Kuhlmann, G. B. F. S. R. M., Kinzelbach, W., 2011. Operational real-time modeling with EnKF of variably saturated subsurface flow including stream-aquifer interaction and parameter updating. Water Resources Research, in press,doi:10.1029/2010WR009480.

Hendricks Franssen, H., Kinzelbach, W., 2008. Real-time groundwater flow modeling with the Ensemble Kalman Filter: Joint estimation of states and parameters and the filter inbreeding problem. Water Resources Research 44 (9), W09408.

Hendricks Franssen, H., Kinzelbach, W., 2009. Ensemble Kalman filtering versus sequential self-calibration for inverse modelling of dynamic groundwater flow systems. Journal of Hydrology 365 (3-4), 261-274.

Hu, B., Meerschaert, M., Barrash, W., Hyndman, D., He, C., Li, X., Guo, L., 2009. Examining the influence of heterogeneous porosity fields on conservative solute transport. Journal of contaminant hydrology 108 (34), $77-88$.

Hu, L. Y., 2000. Gradual deformation and iterative calibration of gaussian-related stochastic models. Math. Geology 32 (1), 87-108. 
Huang, C., Hu, B. X., Li, X., Ye, M., 2008. Using data assimilation method to calibrate a heterogeneous conductivity field and improve solute transport prediction with an unknown contamination source. Stochastic Environmental Research and Risk Assessment 23 (8), 1155-1167.

Huang, H., Hu, B., Wen, X., Shirley, C., 2004. Stochastic inverse mapping of hydraulic conductivity and sorption partitioning coefficient fields conditioning on nonreactive and reactive tracer test data. Water Resources Research 40 (1), W01506.

Jiang, X., Wan, L., Cardenas, M., Ge, S., Wang, X., 2010. Simultaneous rejuvenation and aging of groundwater in basins due to depth-decaying hydraulic conductivity and porosity. Geophysical Research Letters 37 (5), L05403.

Journel, A., 1974. Geostatistics for conditional simulation of ore bodies. Economic Geology 69 (5), 673.

Kitanidis, P., 1995. Quasi-linear geostatistical theory for inversing. Water Resources Research 31 (10), 24112419.

LaVenue, A. M., Ramarao, B. S., de Marsily, G., Marietta, M. G., 1995. Pilot point methodology for automated calibration of an ensemble of conditionally simulated transmissivity fields, 2, Application. Water Resour. Res. 31 (3), 495-516.

Li, L., Zhou, H., Gómez-Hernández, J. J., 2011a. A comparative study of three-dimensional hydrualic conductivity upscaling at the macrodispersion experiment (MADE) site, on columbus air force base in mississippi (USA). Journal of Hydrology, doi:10.1016/j.jhydrol.2011.05.001.

Li, L., Zhou, H., Gómez-Hernández, J. J., 2011b. Transport upscaling using multi-rate mass transfer in three-dimensional highly heterogeneous porous media. Advances in Water Resources 34 (4), 478-489.

Li, L., Zhou, H., Hendricks Franssen, H., Gómez-Hernández, J. J., 2011c. Modeling transient flow by coupling ensemble kalman filtering and upscaling. Water Resources Research, submitted.

Liu, G., Chen, Y., Zhang, D., 2008. Investigation of flow and transport processes at the MADE site using ensemble kalman filter. Advances in Water Resources 31 (7), 975-986.

Llopis-Albert, C., Capilla, J., 2009. Gradual conditioning of non-Gaussian transmissivity fields to flow and mass transport data: 2. Demonstration on a synthetic aquifer. Journal of Hydrology 371 (1-4), 53-65. 
Mackay, D., Freyberg, D., Roberts, P., Cherry, J., 1986. A natural gradient experiment on solute transport in a sand aquifer: 1. Approach and overview of plume movement. Water Resources Research 22 (13), $2017-2029$.

McLaughlin, D., Townley, L., 1996. A reassessment of the groundwater inverse problem. Water Resources Research 32 (5), 1131-1161.

Medina, A., Carrera, J., 1996. Coupled estimation of flow and solute transport parameters. Water Resources Research 32 (10), 3063-3076.

Naevdal, G., Johnsen, L., Aanonsen, S., Vefring, E., 2005. Reservoir monitoring and continuous model updating using ensemble kalman filter. SPE Journal 10 (1).

Naff, R., Haley, D., Sudicky, E., 1998. High-resolution Monte Carlo simulation of flow and conservative transport in heterogeneous porous media 1. Methodology and flow results. Water Resources Research $34(4), 663-677$.

Nowak, W., 2009. Best unbiased ensemble linearization and the quasi-linear kalman ensemble generator. Water Resources Research 45 (4), W04431.

Oliver, D., Cunha, L., Reynolds, A., 1997. Markov chain Monte Carlo methods for conditioning a permeability field to pressure data. Mathematical Geology 29 (1), 61-91.

Ramarao, B. S., LaVenue, A. M., de Marsily, G., Marietta, M. G., 1995. Pilot point methodology for automated calibration of an ensemble of conditionally simulated transmissivity fields, 1, Theory and computational experiments. Water Resour. Res. 31 (3), 475-493.

Reichle, R., Walker, J., Koster, R., Houser, P., 2002. Extended versus ensemble Kalman filtering for land data assimilation. Journal of hydrometeorology 3, 728-740.

Riva, M., Guadagnini, A., Fernandez-Garcia, D., Sanchez-Vila, X., Ptak, T., 2008. Relative importance of geostatistical and transport models in describing heavily tailed breakthrough curves at the lauswiesen site. Journal of Contaminant Hydrology 101 (1-4), 1-13.

Sahuquillo, A., Capilla, J. E., Gómez-Hernández, J. J., Andreu, J., 1992. Conditional simulation of transmissivity fields honouring piezometric head data. In: Blair, W. R., Cabrera, E. (Eds.), Hydraulic Engineering Software IV, Fluid Flow Modeling. Vol. II. Elsevier Applied Science, London, UK, pp. 201-214. 
Schöniger, A., Nowak, W., Hendricks Franssen, H. J., 2011. Parameter estimation by ensemble Kalman filters with transformed data: approach and application to hydraulic tomography, in preparation for Water Resources Research.

Schwede, R., Cirpka, O., 2009. Use of steady-state concentration measurements in geostatistical inversion. Advances in Water Resources 32 (4), 607-619.

Strebelle, S., 2002. Conditional simulation of complex geological structures using multiple-point statistics. Mathematical Geology 34 (1), 1-21.

Sun, A. Y., Morris, A. P., Mohanty, S., Jul. 2009. Sequential updating of multimodal hydrogeologic parameter fields using localization and clustering techniques. Water Resources Research 45, 15 PP.

Wen, X., Deutsch, C., Cullick, A., 2002. Construction of geostatistical aquifer models integrating dynamic flow and tracer data using inverse technique. Journal of Hydrology 255 (1-4), 151-168.

Wen, X. H., Chen, W., 2005. Real-time reservoir model updating using ensemble Kalman filter. In: SPE reservoir simulation symposium.

Yeh, W., 1986. Review of parameter identification procedures in groundwater hydrology: The inverse problem. Water Resources Research 22 (2), 95-108.

Zheng, C., Wang, P., TUSCALOOSA., A. U., 1999. MT3DMS: A modular three-dimensional multispecies transport model for simulation of advection, dispersion, and chemical reactions of contaminants in groundwater systems; Documentation and user's guide.

Zhou, H., Gómez-Hernández, J. J., Hendricks Franssen, H., Li, L., 2011a. Handling nongaussian distributions with Ensemble Kalman Filter. Advances in Water Resources, in press, doi:10.1016/j.advwatres.2011.04.014.

Zhou, H., Li, L., Gómez-Hernández, J. J., 2010. Three-dimensional hydraulic conductivity upscaling in groundwater modelling. Computers \& Geosciences 36 (10), 1224-1235.

Zhou, H., Li, L., Hendricks Franssen, H., Gómez-Hernández, J. J., 2011b. Pattern recongition in a bimodal aquifer with normal-score Ensemble Kalman Filter. Mathematical Geosciences, under review.

Zimmerman, D., De Marsily, G., Gotway, C., Marietta, M., Axness, C., Beauheim, R., Bras, R., Carrera, J., Dagan, G., Davies, P., et al., 1998. A comparison of seven geostatistically based inverse approaches to 

34 (6), 1373-1413. 

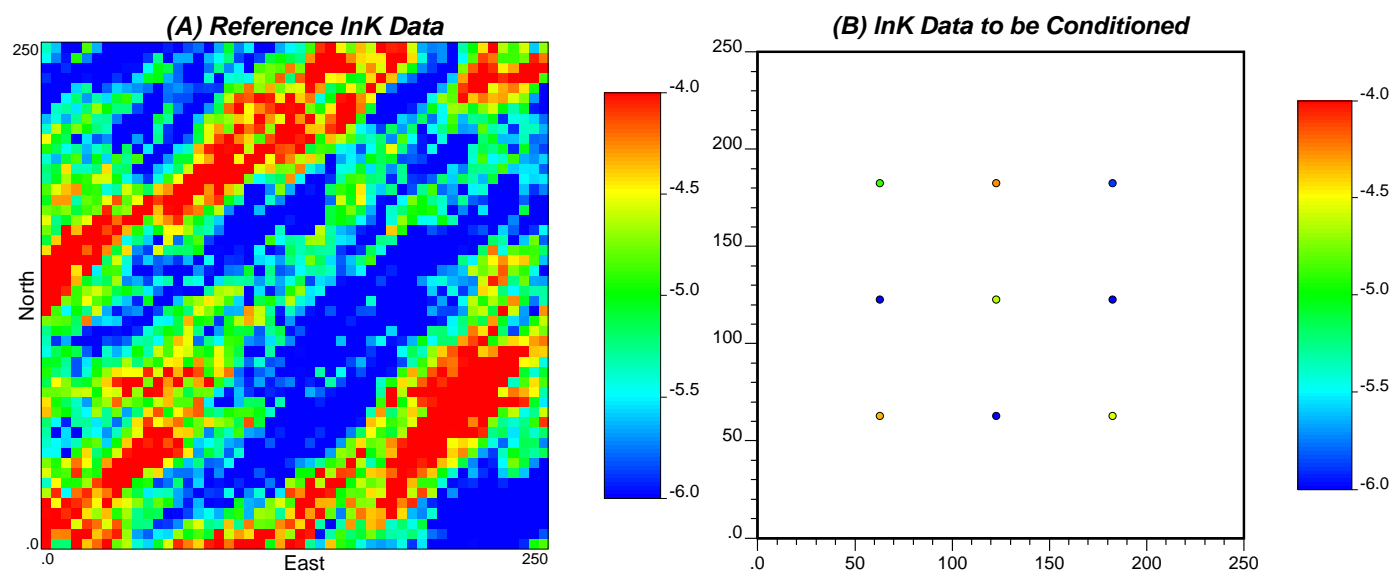

(C) Reference porosity Data
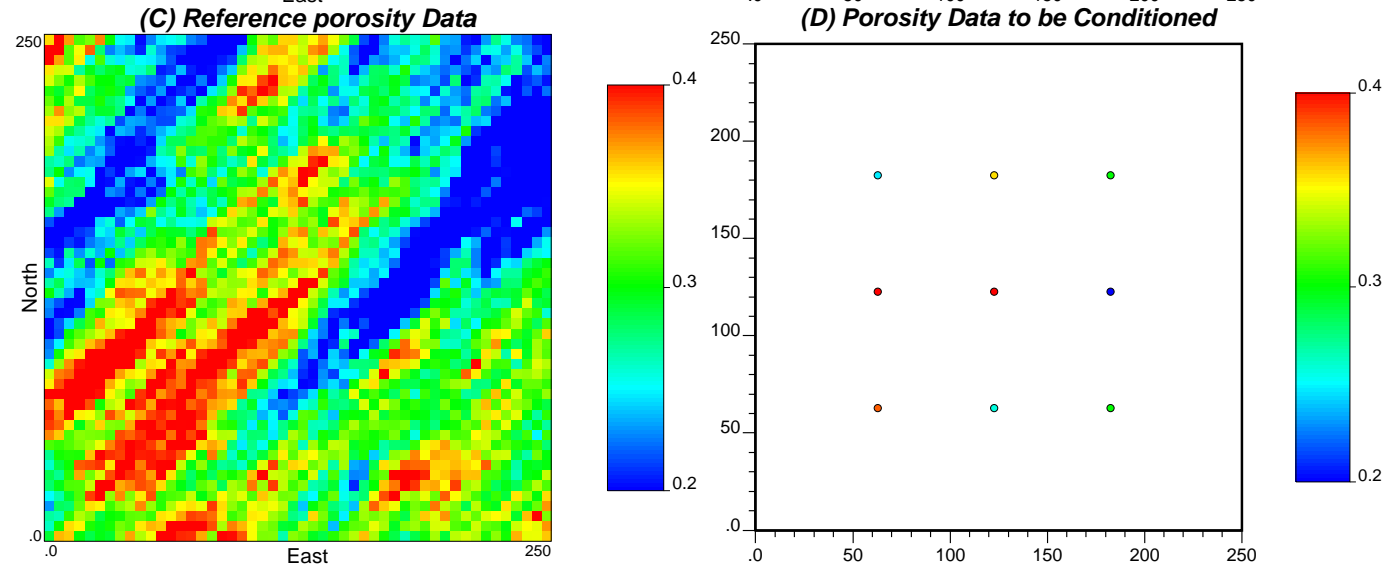

Figure 1: (A) Reference $\ln K$ field, (B) Conditioning $\ln K$ data, (C) Reference porosity $(\phi)$ field, (D) Conditioning porosity $(\phi)$ data. 


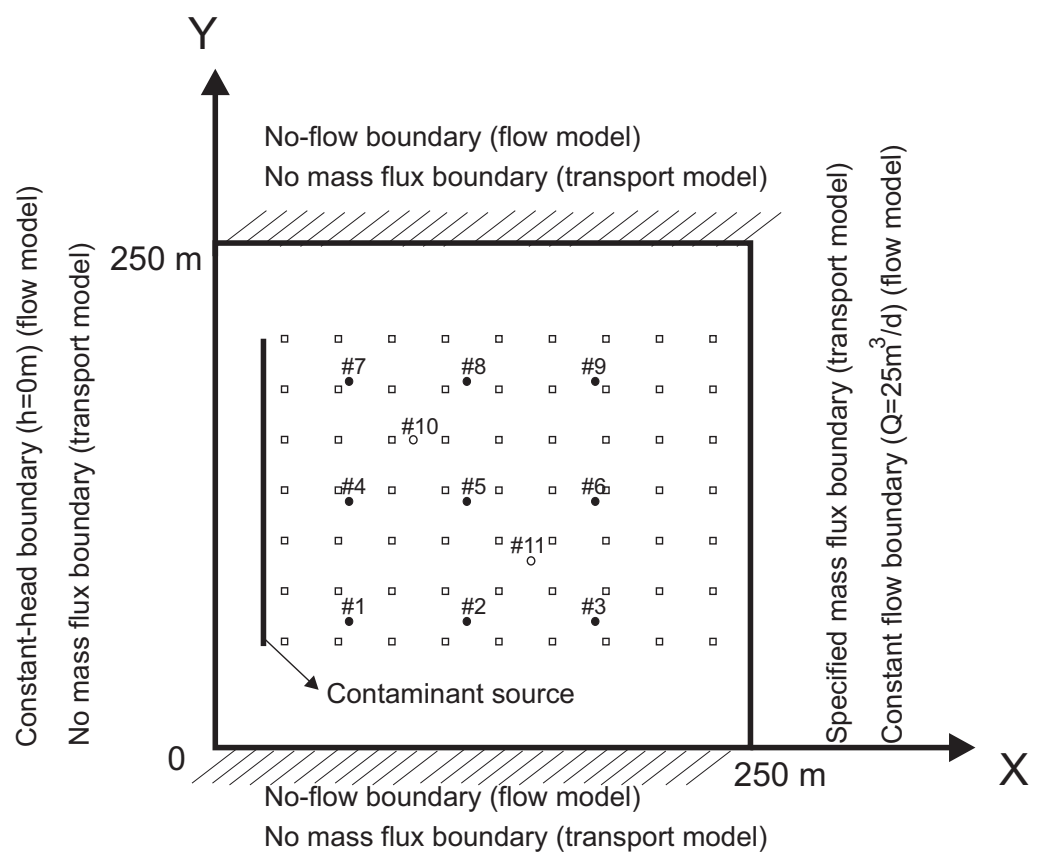

Figure 2: Sketch of the flow and transport simulation with boundary conditions and observation and prediction wells. Filled circles correspond to the pressure head observation wells (\#1-\#9); Open circles denote the control wells (\#10-\#11). Empty squares indicate the wells where concentration is sampled. 

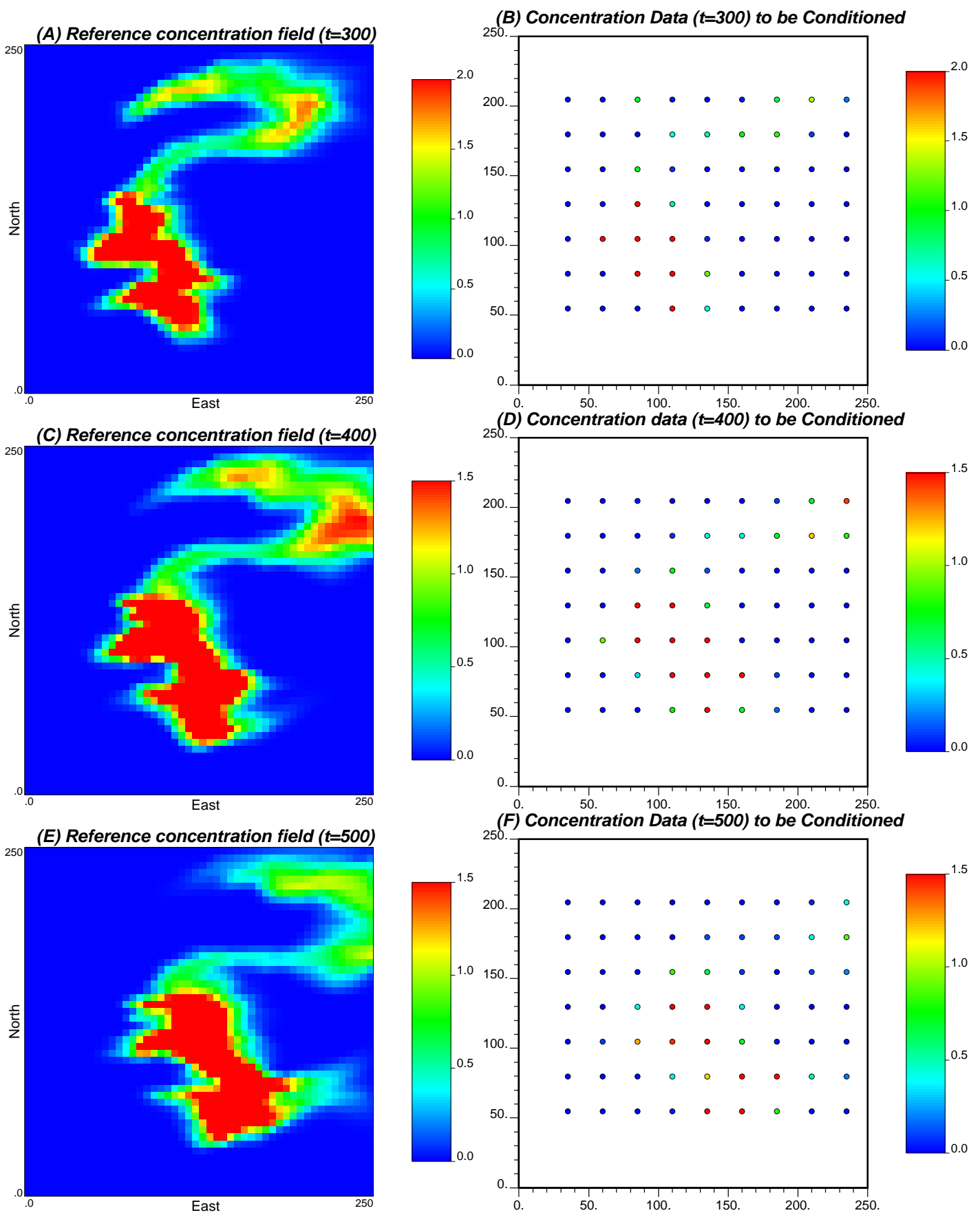

Figure 3: Reference concentration fields at time 300(A), 400(C) and 500(E) days. Conditioning concentration data at time 300 (B), $400(\mathrm{D})$, and $500(\mathrm{~F})$ days. 
S1: mean of InK

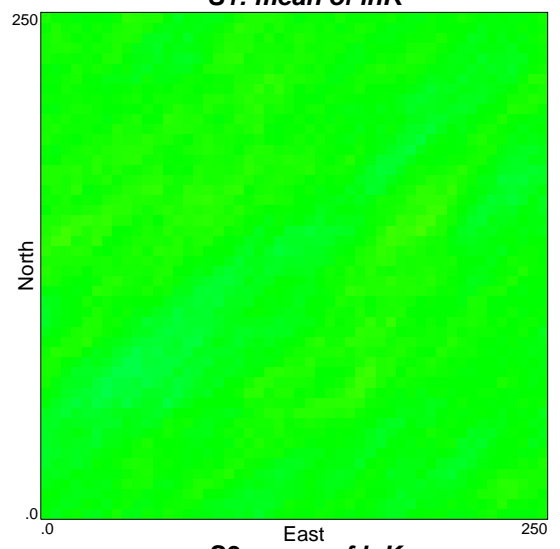

S3: mean of InK

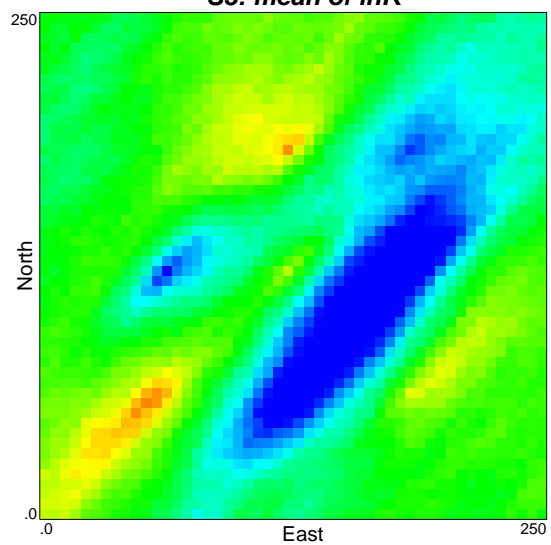

S5: mean of InK

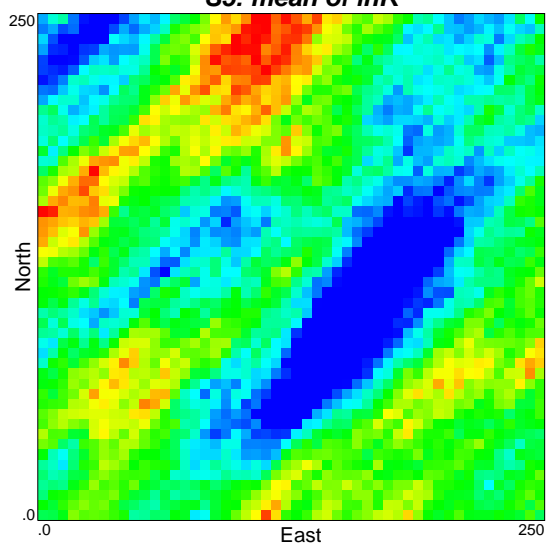

S2: mean of InK
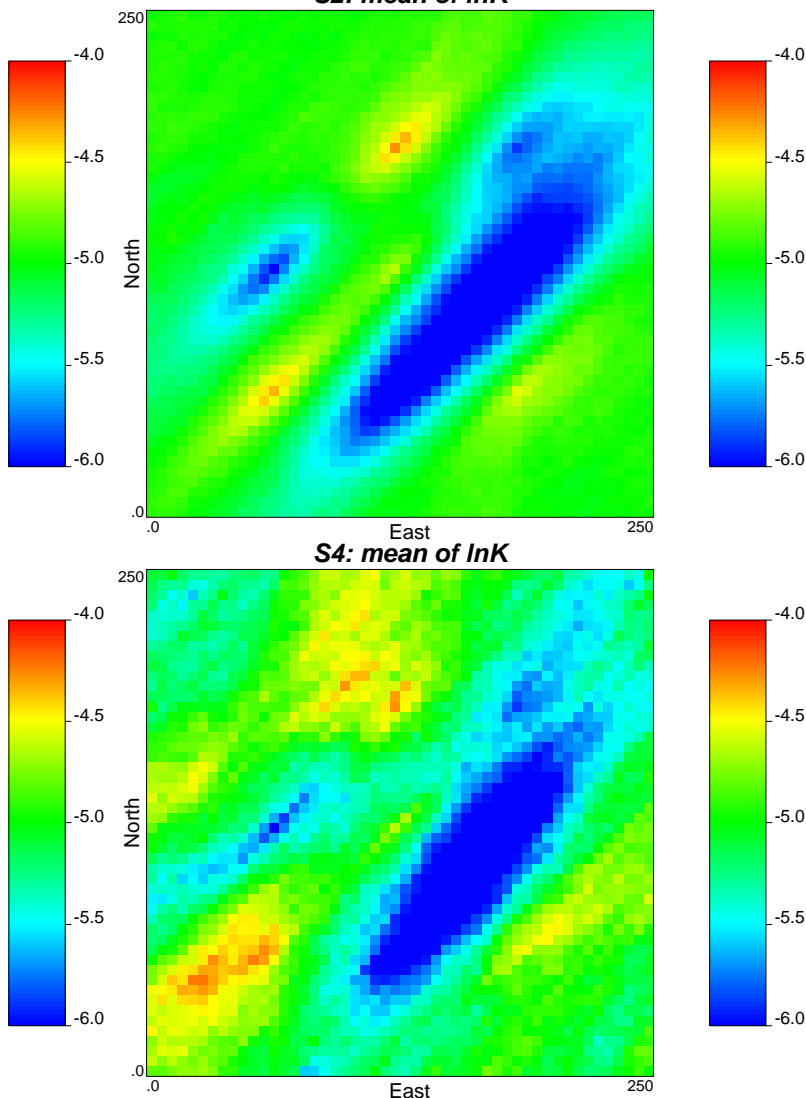

S6: mean of InK
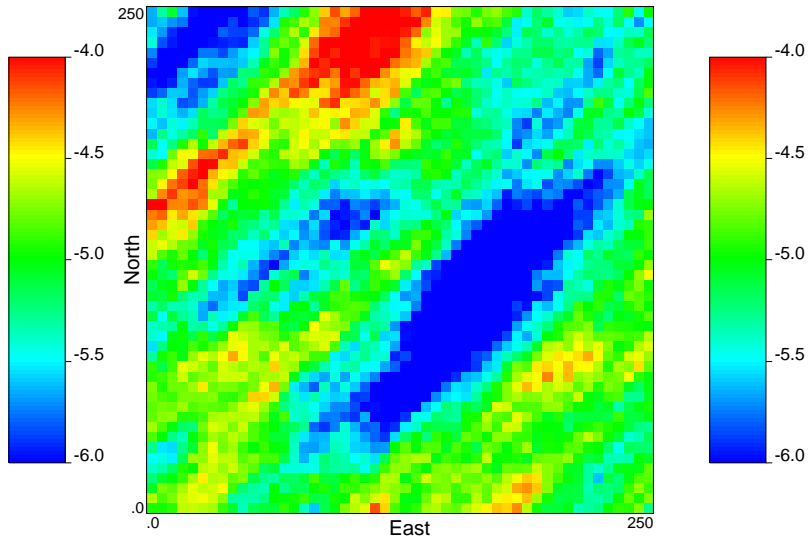

Figure 4: Ensemble average logconductivity fields for the different scenarios. 
S1: variance of InK

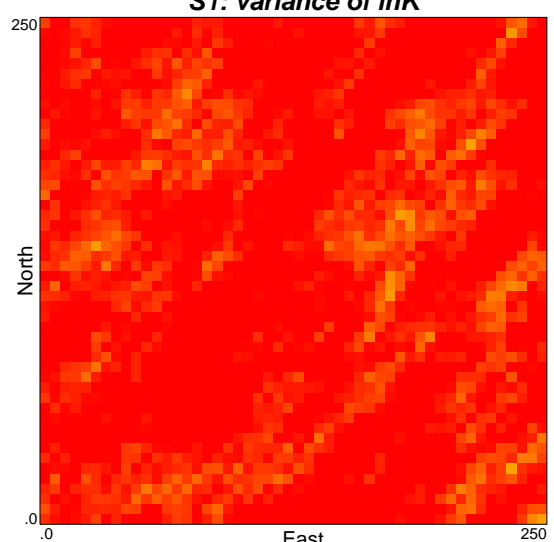

S3: variance of InK

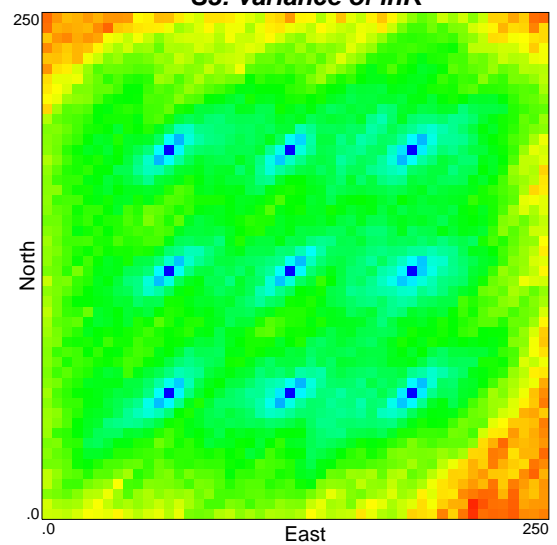

S5: variance of InK

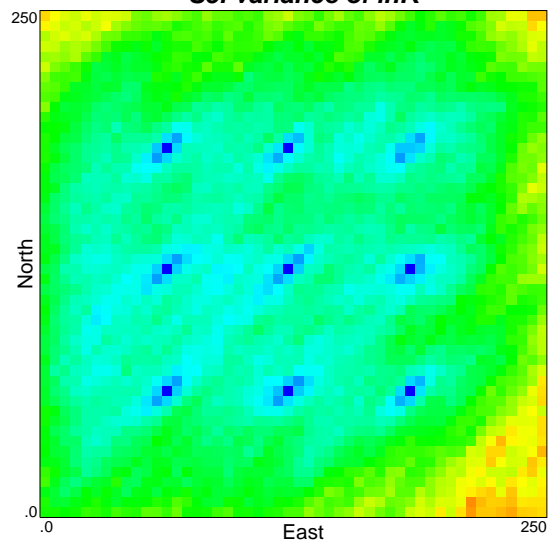

S2: variance of InK

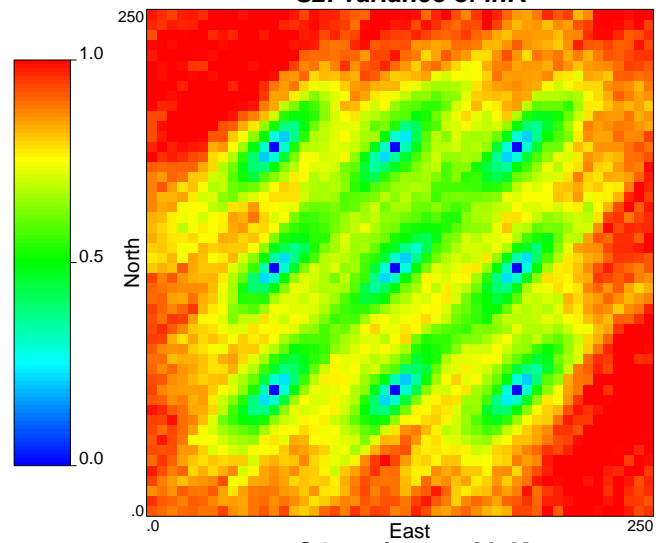

S4: variance of InK

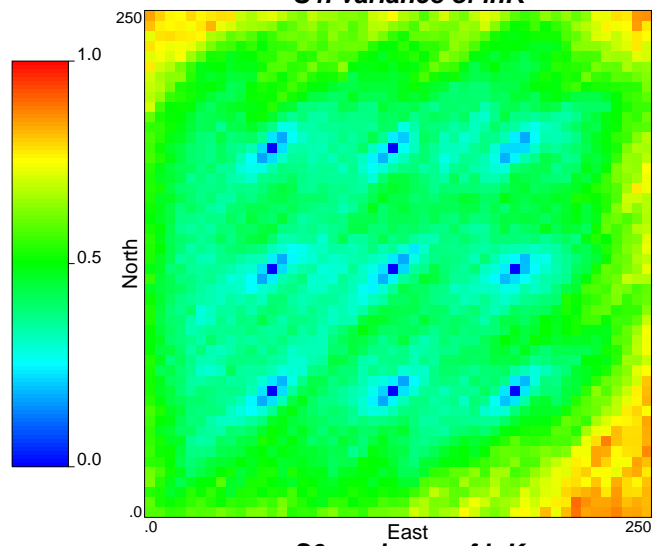

S6: variance of InK

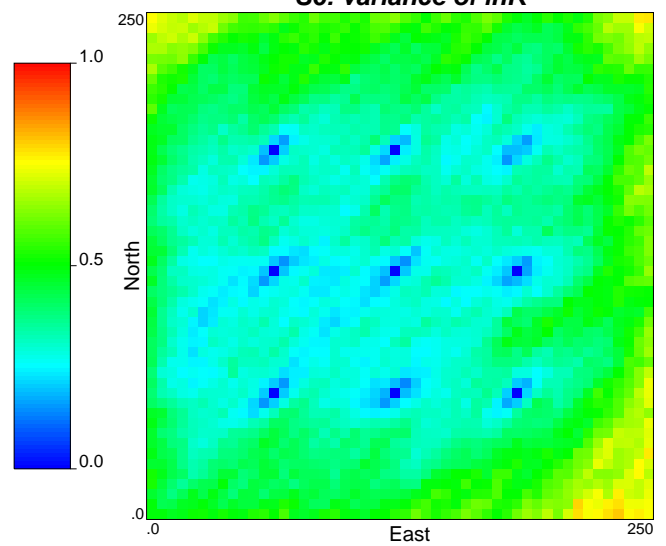

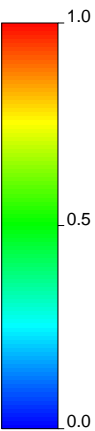
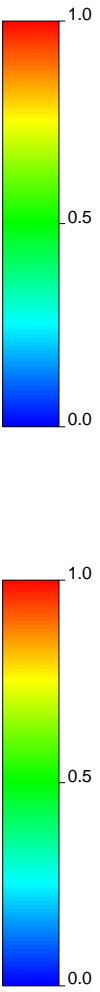

Figure 5: Ensemble logconductivity variance fields for the different scenarios 
S1: mean of porosity

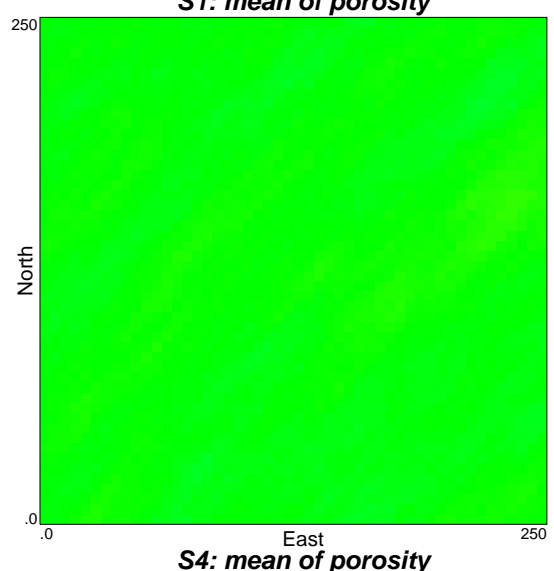

S4: mean of porosity

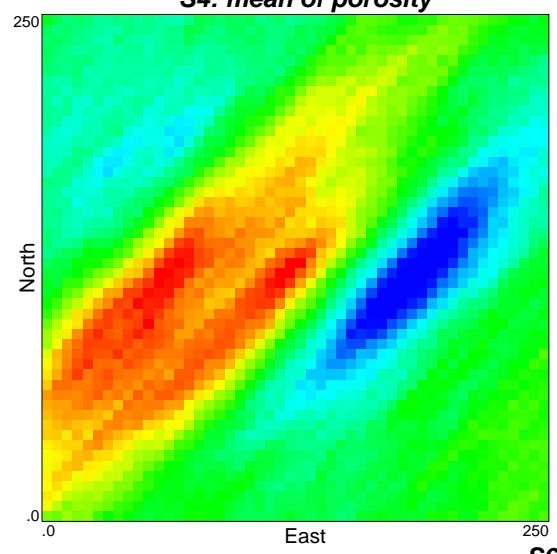

S2: mean of porosity

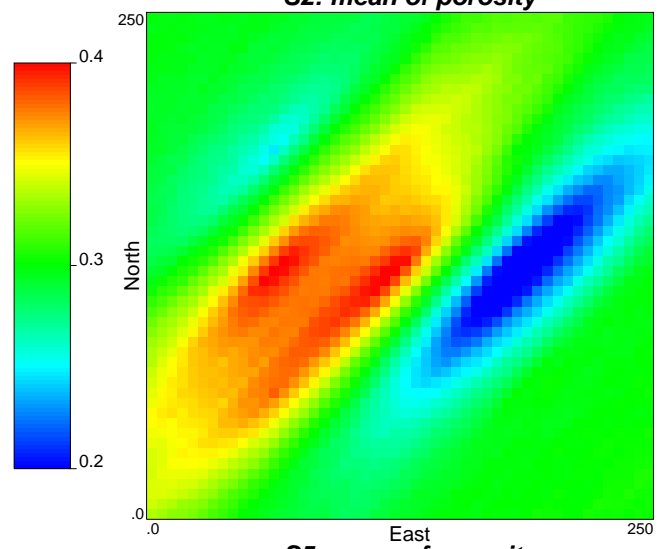

S5: mean of porosity
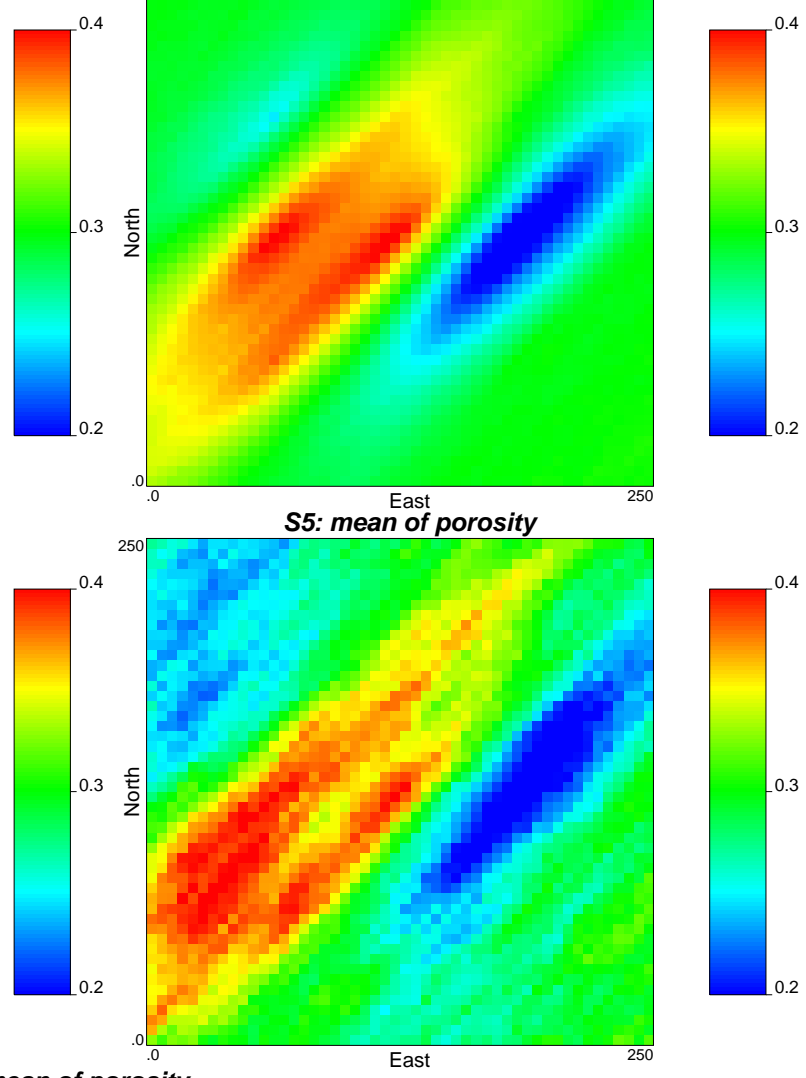
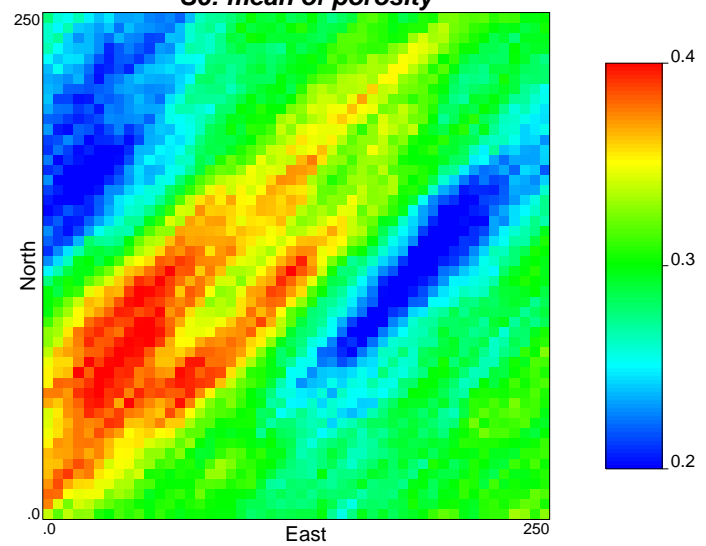

Figure 6: Ensemble average porosity fields for the different scenarios. 

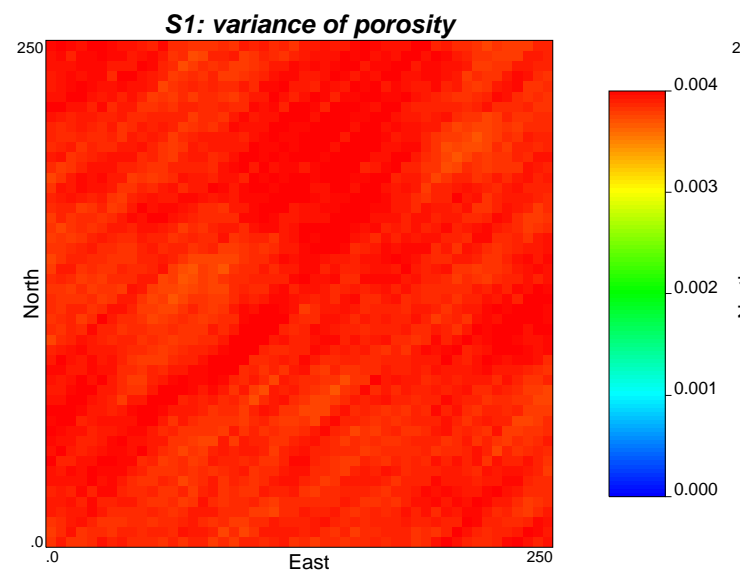

S2: variance of porosity
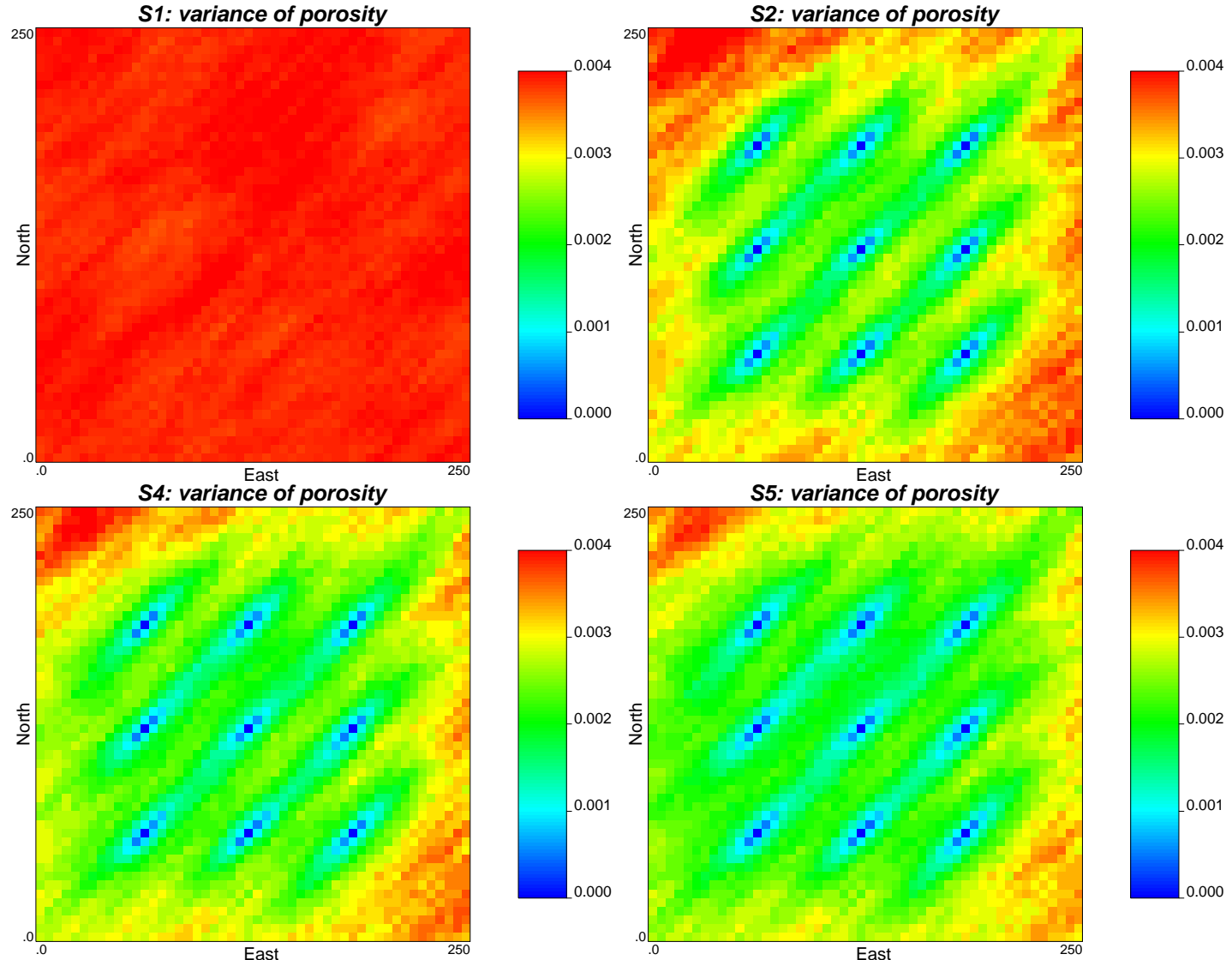

S5: variance of porosity
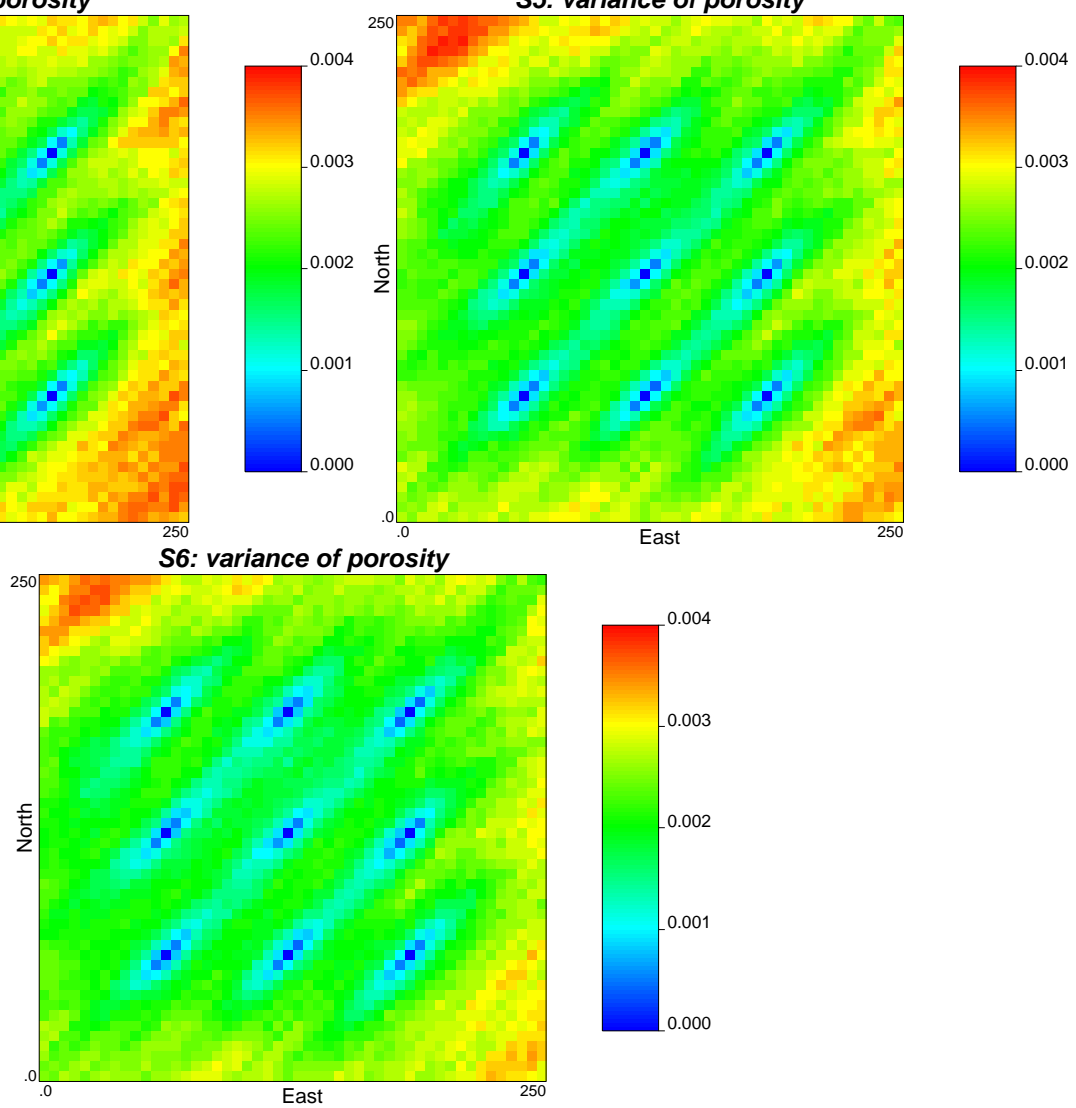

Figure 7: Ensemble porosity variance fields for the different scenarios. 

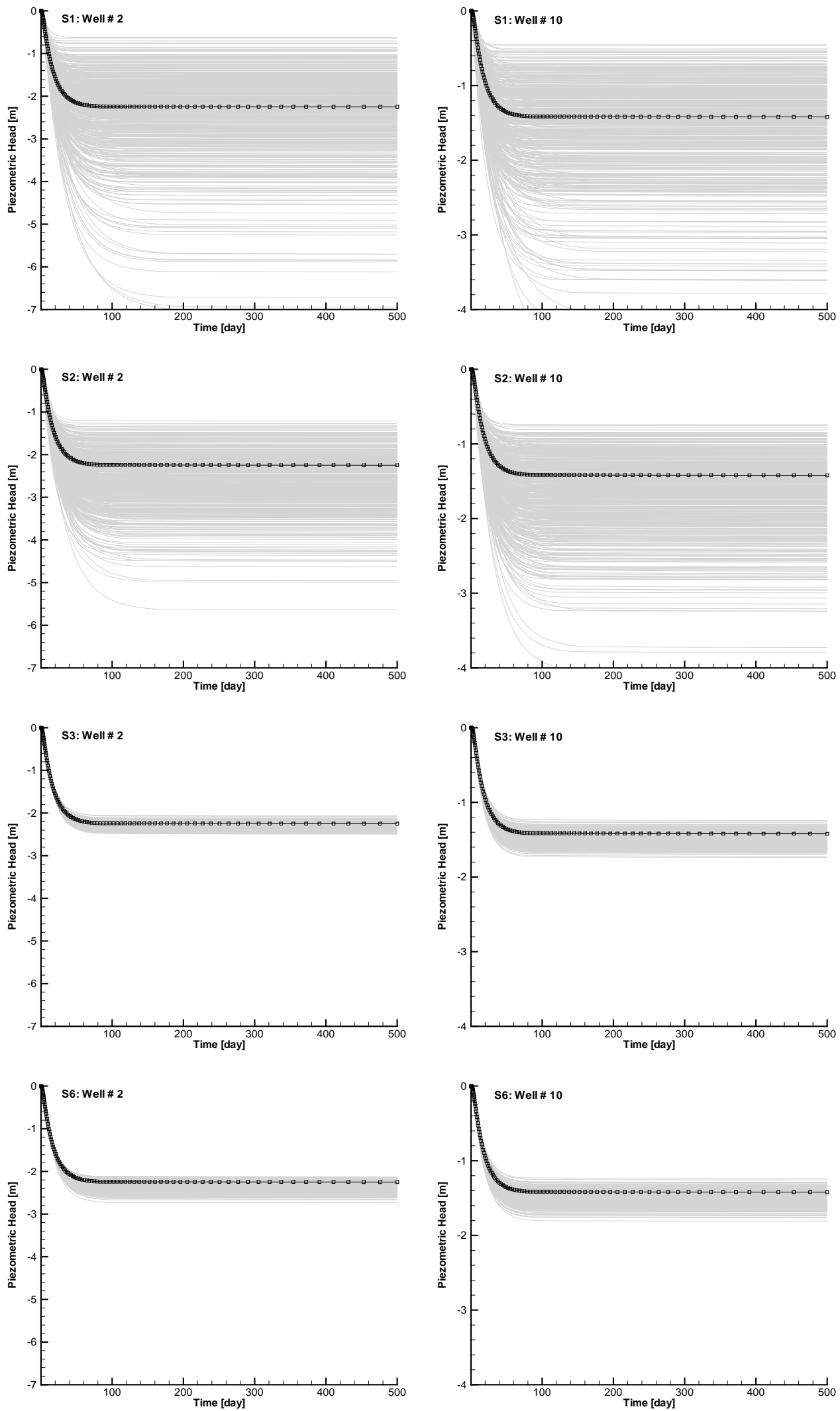

Figure 8: Piezometric head time series for the reference field 28 lack) and simulated ones (gray lines) for the S1,S2,S3 and S6 scenarios at the conditioning well W2 (left column) and verification well W10 (right column). 


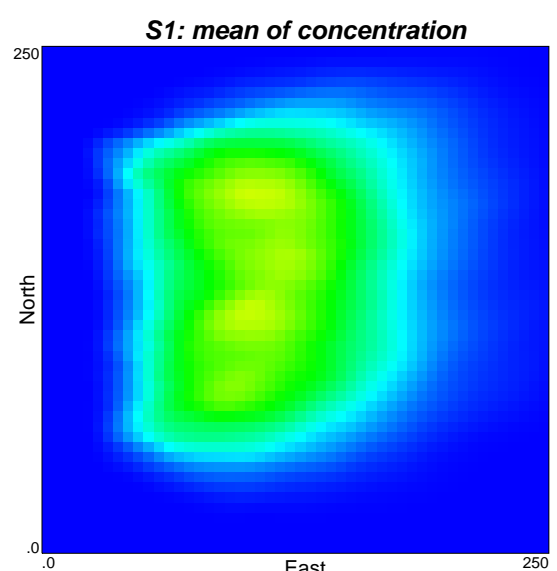

S3: mean of concentration

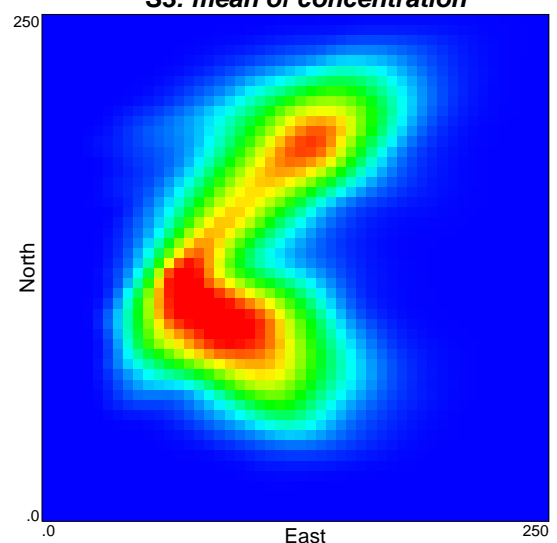

S5: mean of concentration

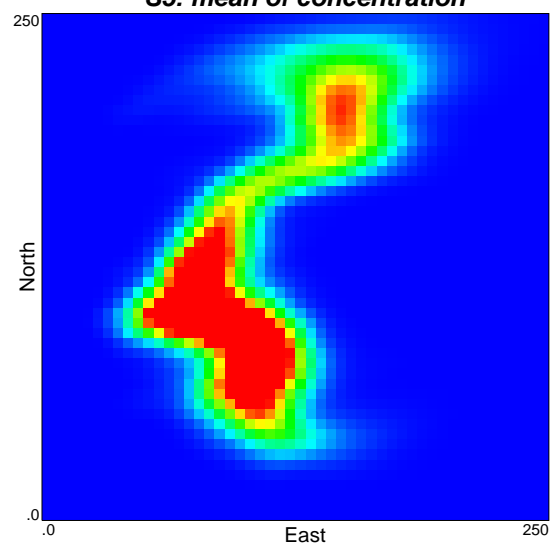

S2: mean of concentration

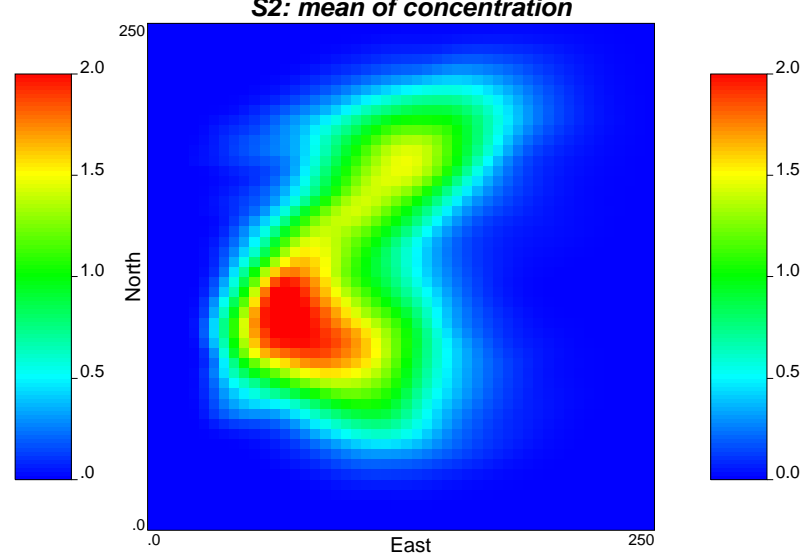

S4: mean of concentration

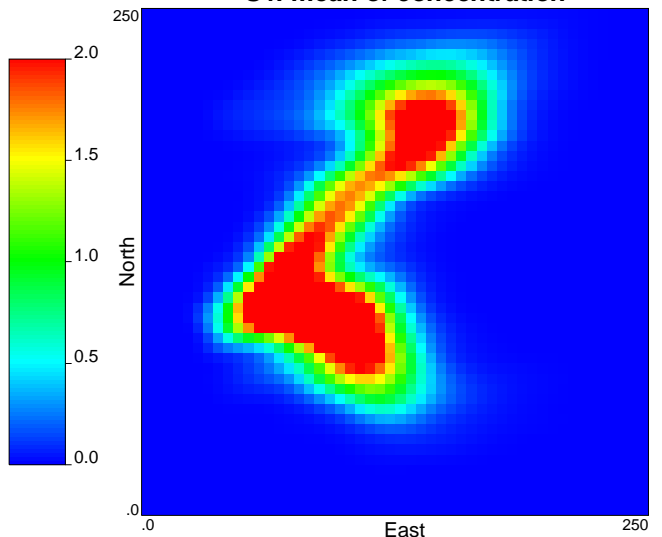

S6: mean of concentration
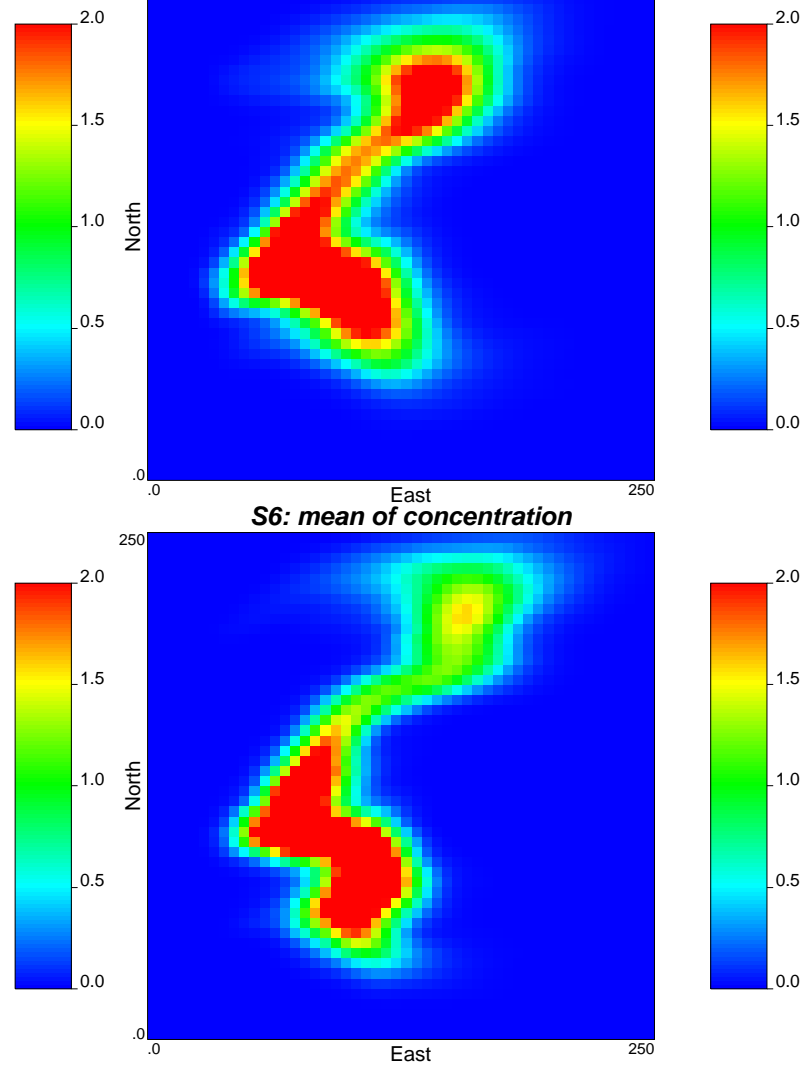

Figure 9: Ensemble average concentration fields at $t=300$ day for the different scenarios. 


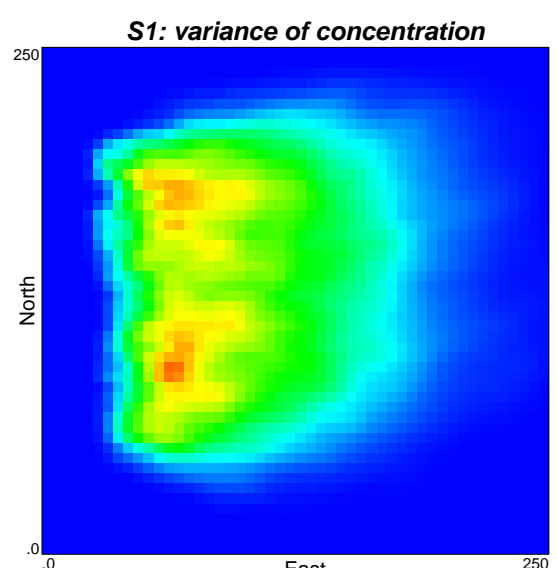

S3: variance of concentration

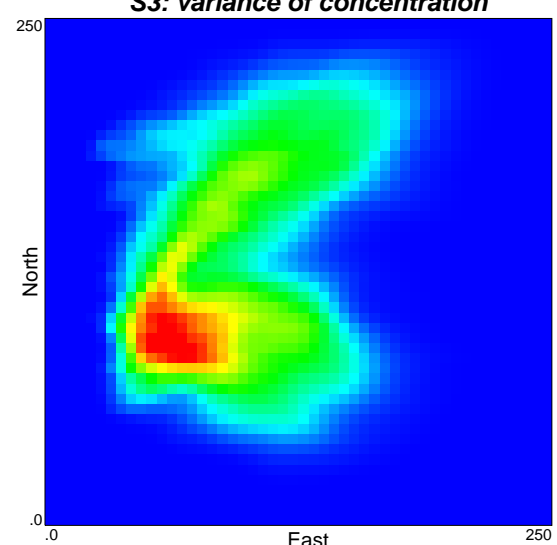

S5: variance of concentration

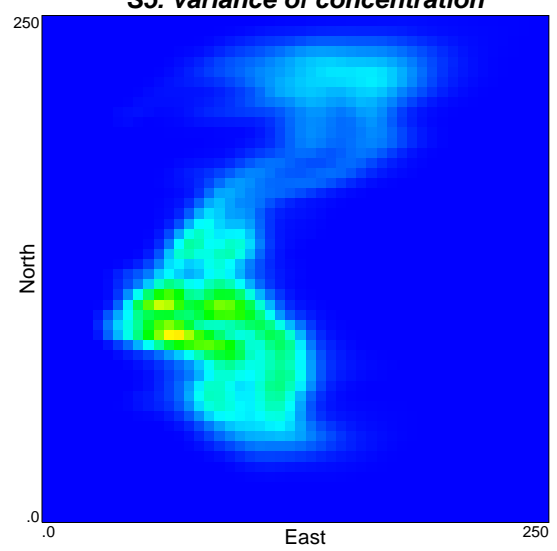

S2: variance of concentration

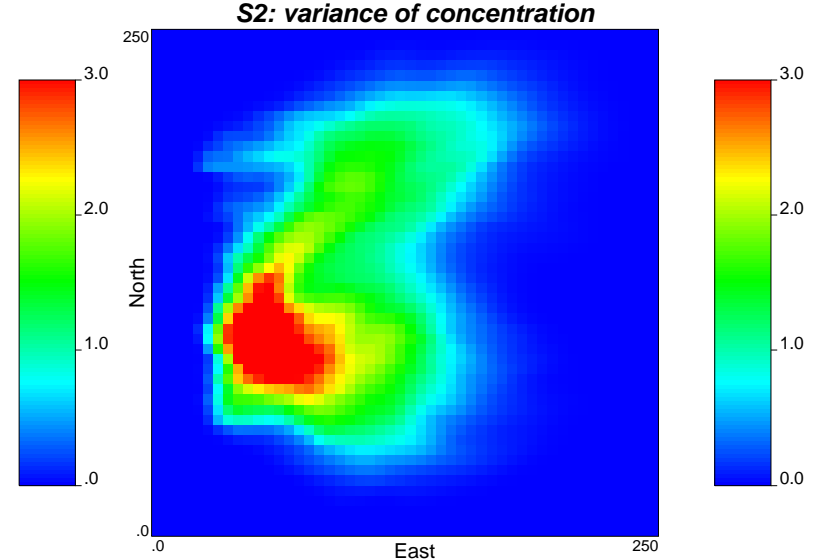

S4: variance of concentration

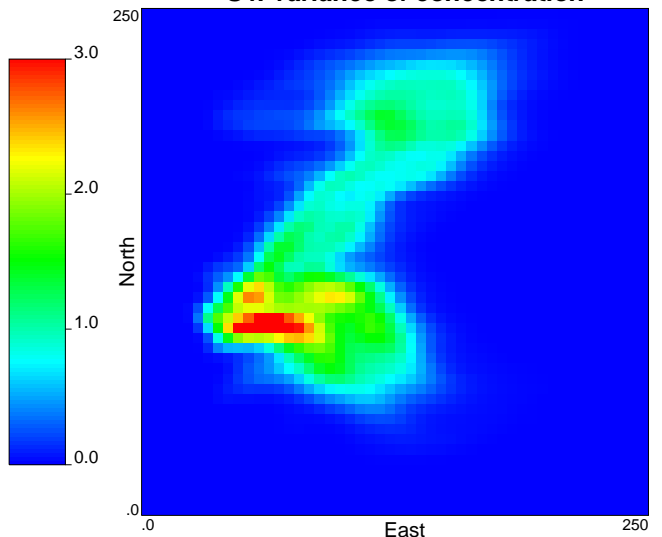

S6: variance of concentration

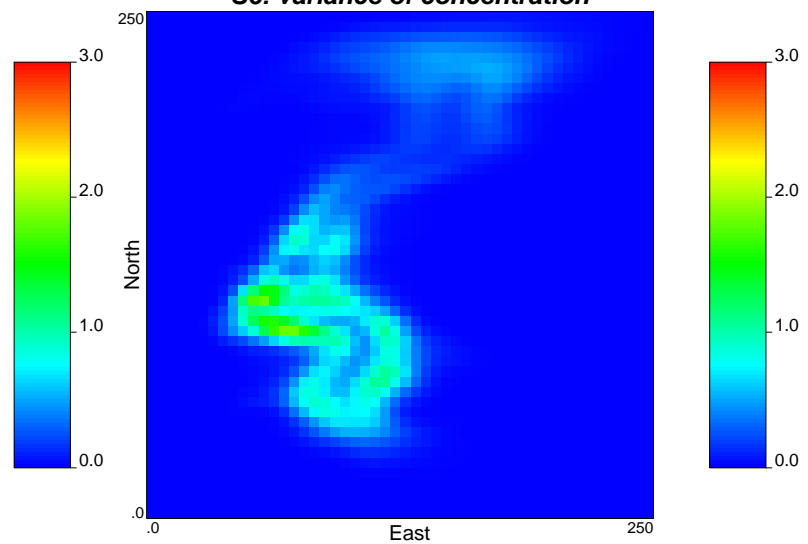

Figure 10: Ensemble variance of concentration fields at $t=300$ day for the different scenarios. 
S1: mean of concentration

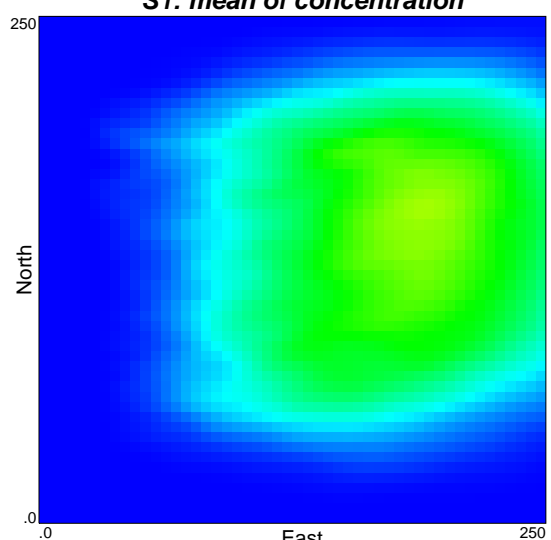

S3: mean of concentration

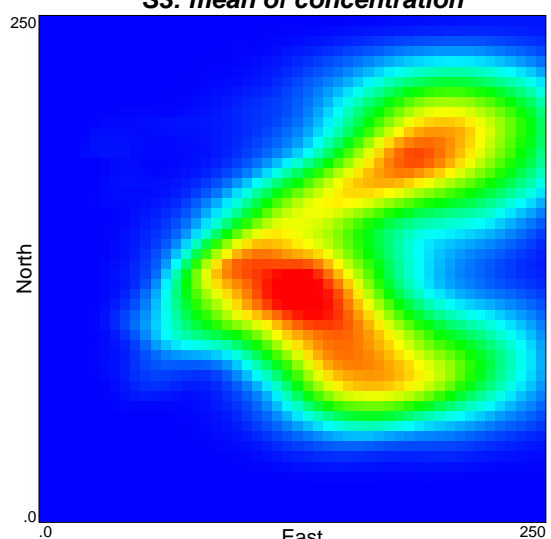

S5: mean of concentration

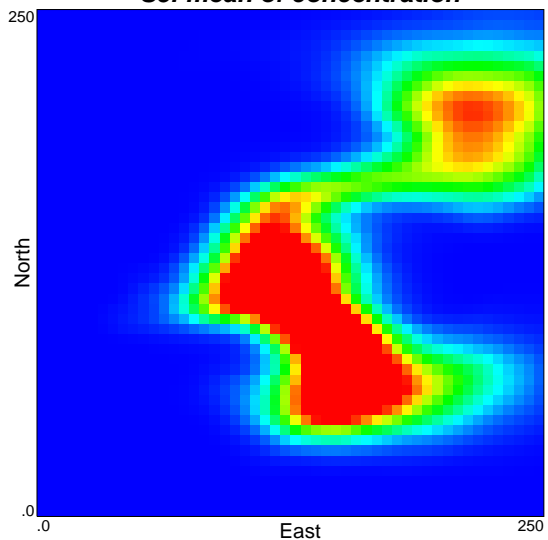

S2: mean of concentration

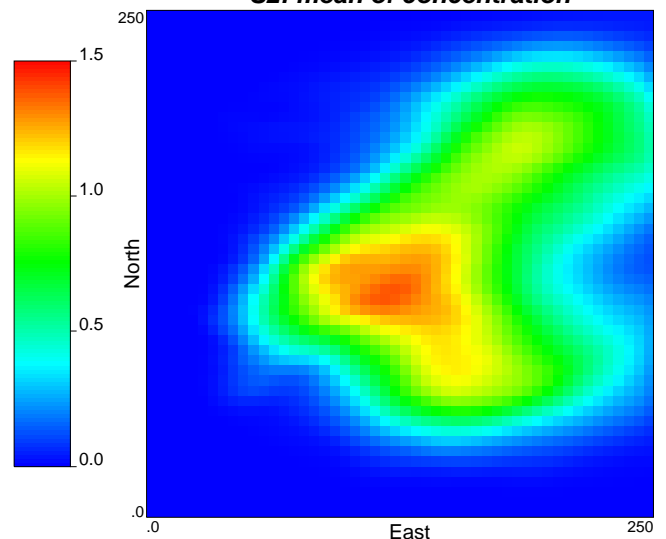

S4: mean of concentration

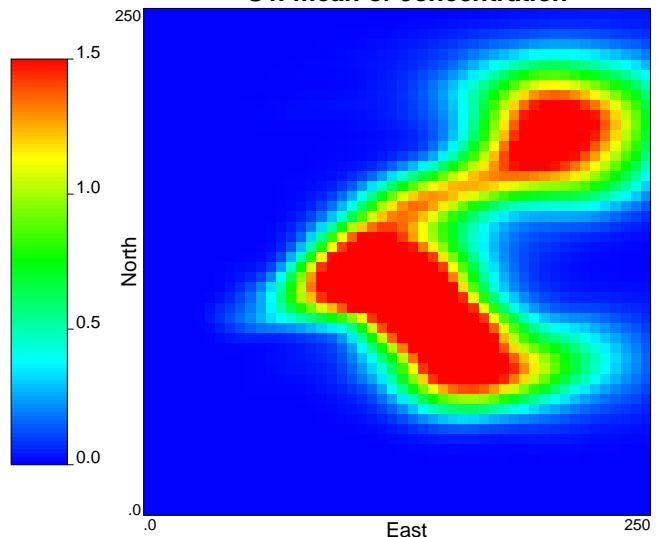

S6: mean of concentration

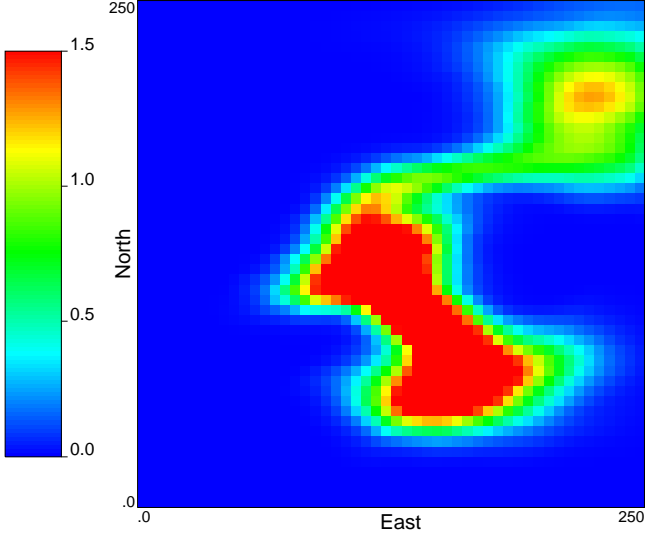

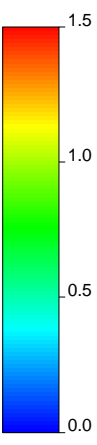
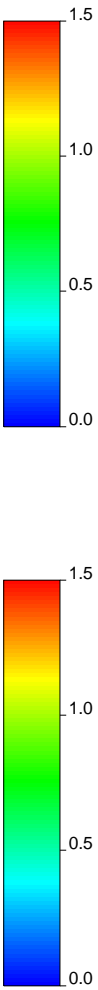

Figure 11: Ensemble average concentration fields at $t=500$ day for the different scenarios. 
S1: variance of concentration

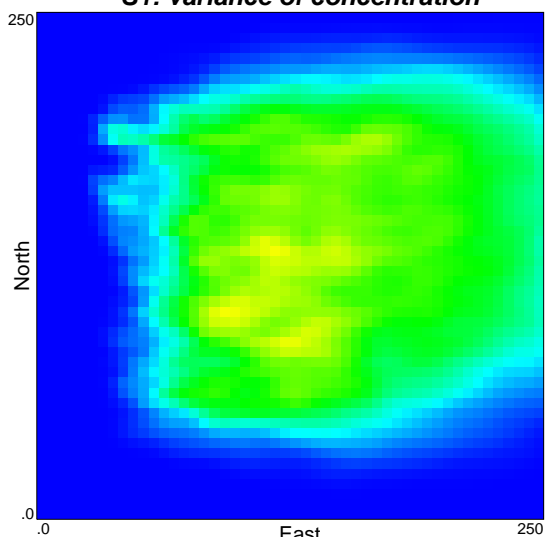

S3: variance of concentration

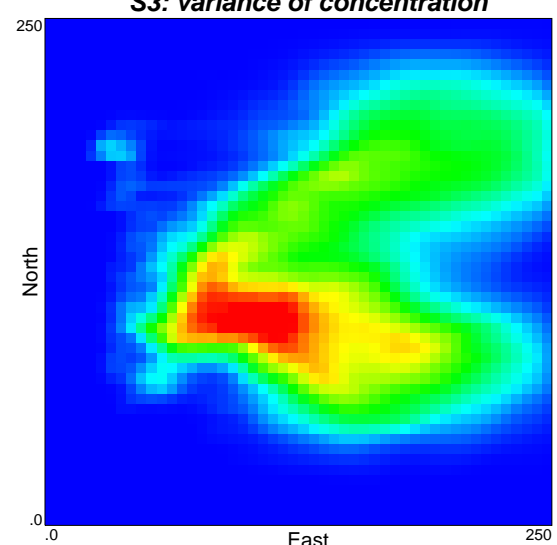

S5: variance of concentration

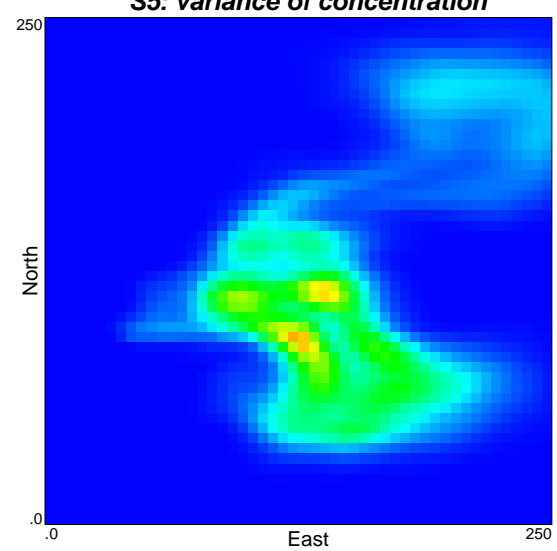

S2: variance of concentration
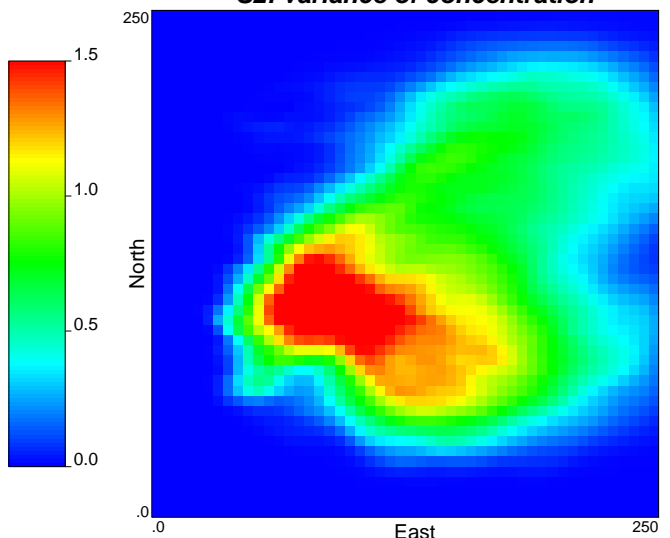

S4: variance of concentration

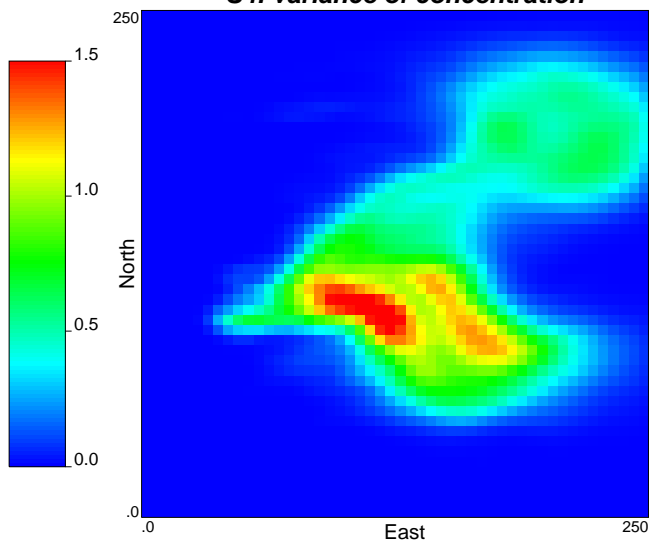

S6: mean of concentration

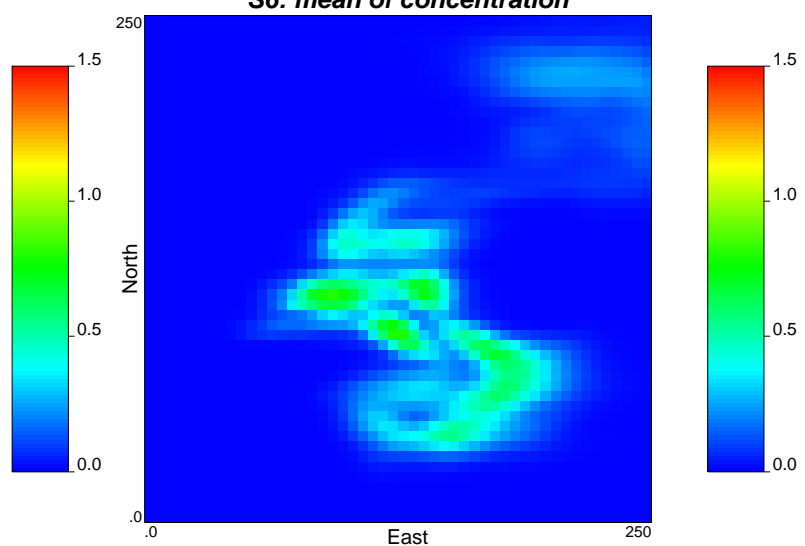

Figure 12: Ensemble variance of concentration fields at $t=500$ day for the different scenarios. 


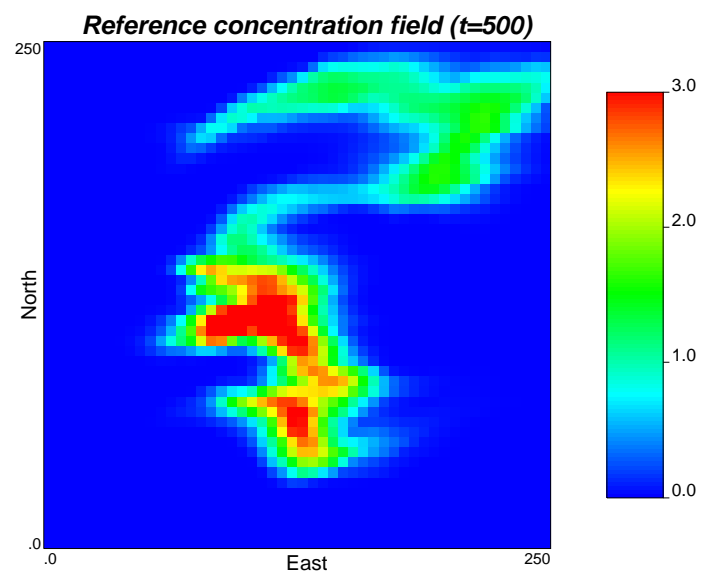

Figure 13: The reference concentration field at $t=500$ days for the reactive transport prediction experiment. 
S2: mean of concentration

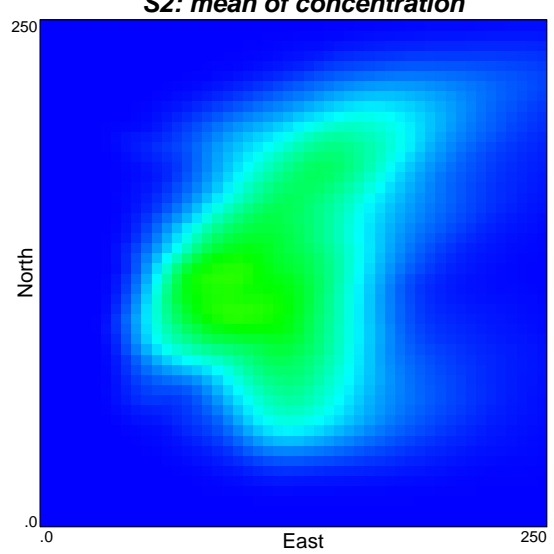

S3: mean of concentration

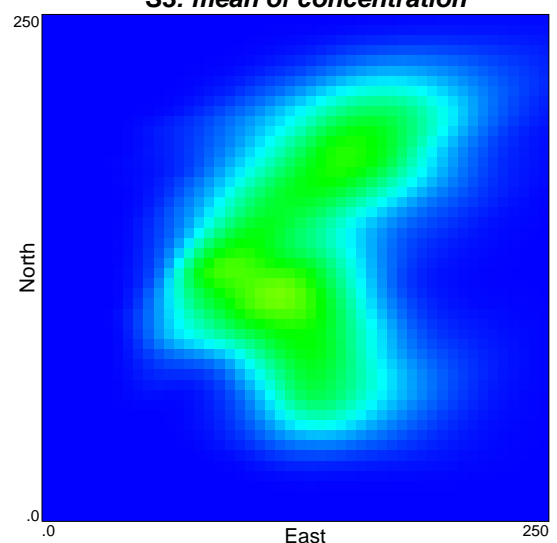

S6: mean of concentration

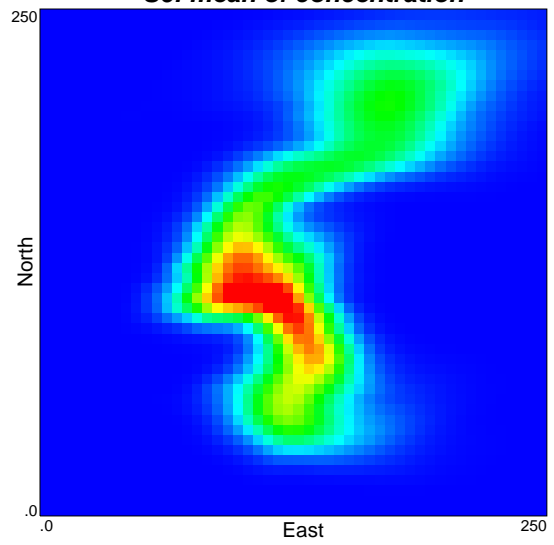

S2: variance of concentration

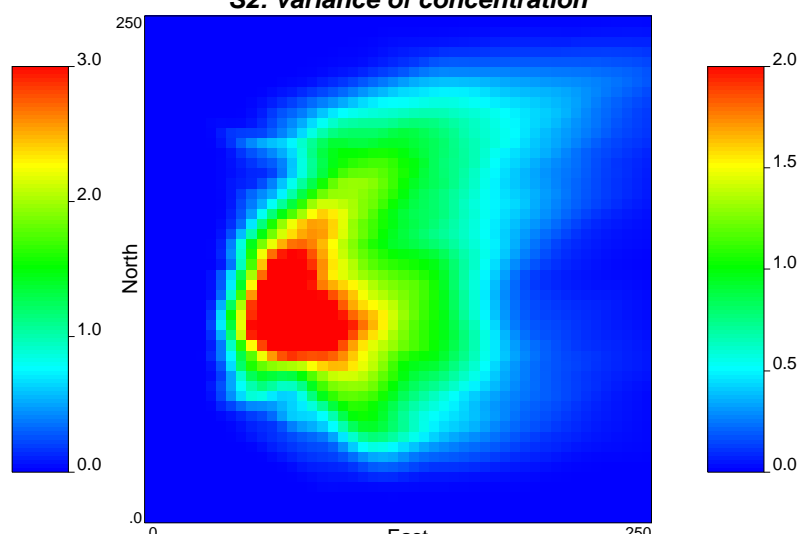

S3: variance of concentration

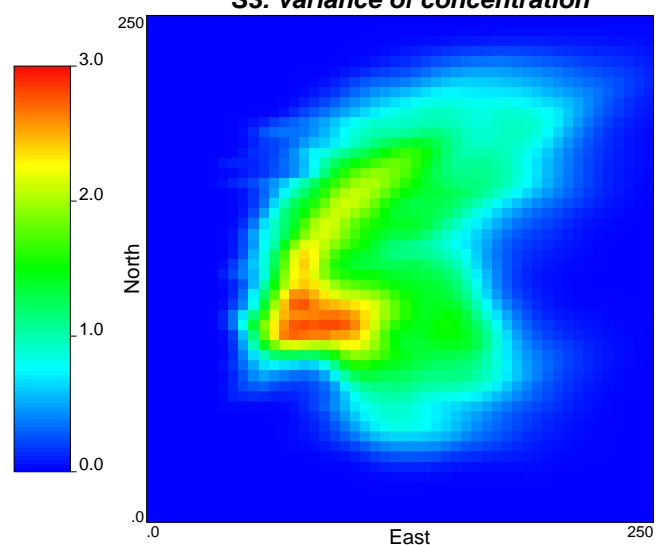

S6: variance of concentration

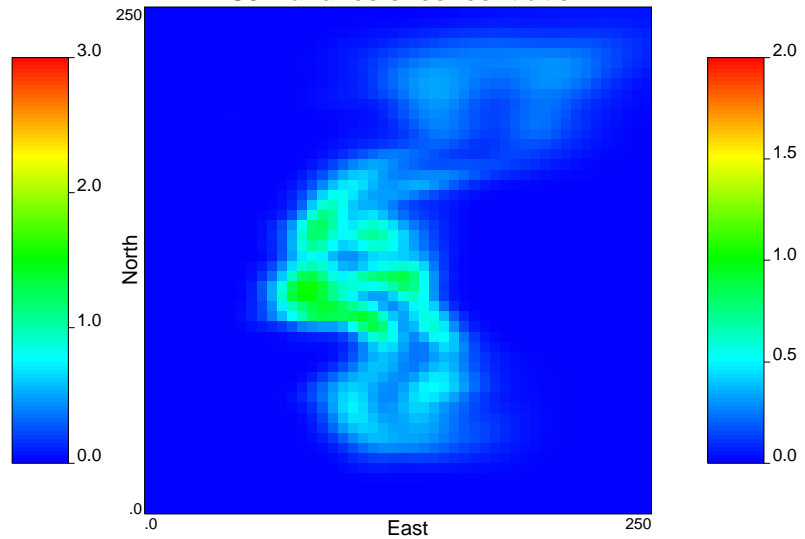

Figure 14: Ensemble mean and variance of concentration fields at $t=500$ day for the S2,S3 and S6. 
Table 1: Parameters of the random functions for modeling the spatial distributions of $\ln K$ and porosity

\begin{tabular}{ccccccc}
\hline & Mean & Variance & Variogram type & $\lambda_{x}[\mathrm{~m}]$ & $\lambda_{y}[\mathrm{~m}]$ & rotation angle $\beta$ \\
\hline $\ln K$ & -5 & 1 & exponential & 180 & 60 & $45^{\circ}$ \\
$\phi$ & 0.3 & 0.0036 & exponential & 240 & 60 & $45^{\circ}$
\end{tabular}

$\beta$ denotes the rotation angle of one clockwise rotation of positive $y$ axis.

Table 2: Definition of scenarios based on the different sets of conditioning data.

\begin{tabular}{lcccccc}
\hline Scenario & S1 & S2 & S3 & S4 & S5 & S6 \\
\hline Hydraulic conductivities $(K)$ & No & Yes & Yes & Yes & Yes & Yes \\
Porosity $(\phi)$ & No & Yes & Yes & Yes & Yes & Yes \\
Dynamic piezometric heads $(\mathrm{h})$ & No & No & Yes & Yes & Yes & Yes \\
Concentrations $(t=300$ day $)$ & No & No & No & Yes & Yes & Yes \\
Concentrations $(t=400$ day) & No & No & No & No & Yes & Yes \\
Concentrations $(t=500$ day $)$ & No & No & No & No & No & Yes \\
\hline
\end{tabular}

Table 3: Bias and spread of $\operatorname{lnK}$ and porosity for the different scenarios.

\begin{tabular}{lcccccc}
\hline Scenario & S1 & S2 & S3 & S4 & S5 & S6 \\
\hline$A A B(\ln K)$ & 1.112 & 0.949 & 0.852 & 0.816 & 0.796 & 0.790 \\
$A E S P(\ln K)$ & 1.001 & 0.874 & 0.728 & 0.680 & 0.650 & 0.624 \\
$A A B(\phi)$ & 0.072 & 0.059 & - & 0.057 & 0.056 & 0.055 \\
$A E S P(\phi)$ & 0.060 & 0.051 & - & 0.049 & 0.047 & 0.046 \\
\hline
\end{tabular}

Table 4: Bias and spread of predicted piezometric heads at time $t=67.7$ days for the different scenarios.

\begin{tabular}{lcccccc}
\hline Scenario & S1 & S2 & S3 & S4 & S5 & S6 \\
\hline$A A B\left(h_{t=67.7}\right)$ & 0.690 & 0.503 & 0.169 & 0.170 & 0.179 & 0.179 \\
$A E S P\left(h_{t=67.7}\right)$ & 0.901 & 0.649 & 0.175 & 0.172 & 0.169 & 0.162 \\
\hline
\end{tabular}

Table 5: Bias and spread of predicted concentrations at time $t=300, t=400, t=500$ days for the different scenarios.

\begin{tabular}{lcccccc}
\hline Scenario & $\mathrm{S} 1$ & $\mathrm{~S} 2$ & $\mathrm{~S} 3$ & $\mathrm{~S} 4$ & $\mathrm{~S} 5$ & $\mathrm{~S} 6$ \\
\hline$A A B\left(c_{t=300}\right)$ & 0.493 & 0.402 & 0.384 & 0.318 & 0.252 & 0.225 \\
$A E S P\left(c_{t=300}\right)$ & 0.781 & 0.703 & 0.652 & 0.496 & 0.400 & 0.337 \\
$A A B\left(c_{t=400}\right)$ & 0.506 & 0.422 & 0.403 & 0.331 & 0.249 & 0.209 \\
$A E S P\left(c_{t=400}\right)$ & 0.710 & 0.662 & 0.613 & 0.470 & 0.371 & 0.300 \\
$A A B\left(c_{t=500}\right)$ & 0.452 & 0.393 & 0.374 & 0.303 & 0.226 & 0.176 \\
$A E S P\left(c_{t=500}\right)$ & 0.634 & 0.624 & 0.577 & 0.457 & 0.358 & 0.274 \\
\hline
\end{tabular}

